\title{
Ceramic Technology of the Asurini do Xingu, Brazil: An Ethnoarchaeological Study of Artifact Variability
}

\author{
Fabíola Andréa Silva
}

Published online: 14 August 2008

C The Author(s) 2008. This article is published with open access at SpringerLink.com

\begin{abstract}
This article presents some of the results of ethnoarchaeological research on ceramic technology I have conducted among the Asurini do Xingu, an Amazonian indigenous population inhabiting a village in the margins of the Xingu River, Pará, Brazil. Based on collected data, presented throughout the article, I discuss the reasons behind the formal, quantitative, spatial and relational variability of the Asurini ceramic vessels. This work will demonstrate that these distinct dimensions of variability are related to the potters' technological choices during the vessels' production process, the ceramic teaching-learning structure, and the type, frequency, method and context of use of the same vessels. I try to make clear the different practical and symbolic aspects that may influence the production, use, reuse, storage and discard processes of the vessels. Furthermore, I compare the Asurini context with other ethnographic contexts and try to distinguish regularities that may serve as interpretative references to the study of archaeological ceramic assemblages.

Resumo Este artigo apresenta alguns resultados da pesquisa etnoarqueológica sobre tecnologia cerâmica que eu tenho conduzido entre os Asurini do Xingu, uma população ceramista amazônica, que ocupa uma aldeia às margens do rio Xingu, Pará, Brasil. A partir dos dados apresentados ao longo deste artigo, discuto os fatores responsáveis pela variabilidade formal, quantitativa, espacial e relacional das vasilhas cerâmicas Asurini. Este trabalho demonstrará que estas distintas dimensões da variabilidade estão relacionadas com as escolhas tecnológicas levadas a cabo pelas ceramistas durante o processo de produção das vasilhas cerâmicas e, ao mesmo tempo, com a estrutura de ensino-aprendizagem e o tipo, freqüência, método e contexto de uso das vasilhas. Tento esclarecer que diferentes aspectos práticos e simbólicos podem influenciar a produção, uso, reuso, estocagem e descarte das vasilhas. Além disso, comparo o contexto Asurini com outros contextos etnográficos e tento distinguir regularidades que possam servir como referências interpretativas para o estudo dos conjuntos arqueológicos cerâmicos.
\end{abstract}

Keywords Ethnoarchaeology $\cdot$ Amazon $\cdot$ Asurini do Xingu Pottery production and use

\section{F. A. Silva $(\bowtie)$}

Museu de Arqueologia e Etnologia, Universidade de São Paulo, Av. Prof. Almeida Prado, 1466,

Cidade Universitária, CEP 0500 São Paulo, SP, Brasil

e-mail: faandrea@usp.br 


\section{Introduction}

Pottery has been one of the main objects of investigation for archaeologists who have long attempted to explain the reasons behind its variability in the archaeological record. Ethnoarchaeology has been at the forefront of this research as it allows us to observe the behavioral aspects and the material consequences of activities related to the production, use, consumption, distribution and discard of ceramic artifacts within different ethnographic contexts. According to Skibo (1999: p. 4), it is through the ethnoarchaeological research that the archaeologists can reach an understanding of the "ceramic production organization and other relations between pottery and people." This article will contribute to an understanding of aspects of the organization of ceramic production with regard to the domestic group and the economic, social, and symbolic relations between pots and their producers and consumers. At the same time, it will demonstrate how different functional, social, and symbolic factors may determine the variability of ceramic artifacts.

This article presents some of the results of an ethnoarchaeological study I have conducted among the Asurini do Xingu, an Amazonian indigenous potteryproducing population inhabiting a village in the margins of the Xingu River, Pará, Brazil (see map). They speak Asurini do Xingu (called only Asurini below), a language from the Tupi-Guarani linguistic family, which is a branch of the Tupi languages. I first met the Asurini in October 1996, when I began my PhD research (Silva 2000). For three years, I visited their village regularly in order to study processes of production, use, storage and discard of pottery. The data appearing in this article come from this period of the research.

Based upon these data, I consider the reasons behind the formal, quantitative, spatial and relational variability of the Asurini vessels. This work will demonstrate that these distinct dimensions of variability are related to the technological choices the potters made during the vessels' production process, the ceramic teachinglearning structure, and the type, frequency, method and context of use of the same vessels. I try to make clear the different practical and symbolic aspects that may influence the production, use, reuse, storage and discard processes of the vessels. Furthermore, I compare Asurini pottery production with other ethnographic cases and try to distinguish regularities that may aid in the interpretation of archaeological ceramics. Archaeologists often make inferences about the past based on fragmented material, which is similar to building "a puzzle with only a few pieces" (Skibo 1992: p. 182). In this sense, ethnoarchaeological studies like this one are an effort to produce data that will help complete this puzzle of the past.

\section{Field Research}

The data presented in this article were collected during the months of October and November 1996, September-November 1997, and March, April and September 1998. Throughout this period of research, I witnessed the production of the ceramic vessels (raw material procurement, selection and preparation of raw material; vessel manufacture, drying, firing and surface finishing), the teaching-learning process of 


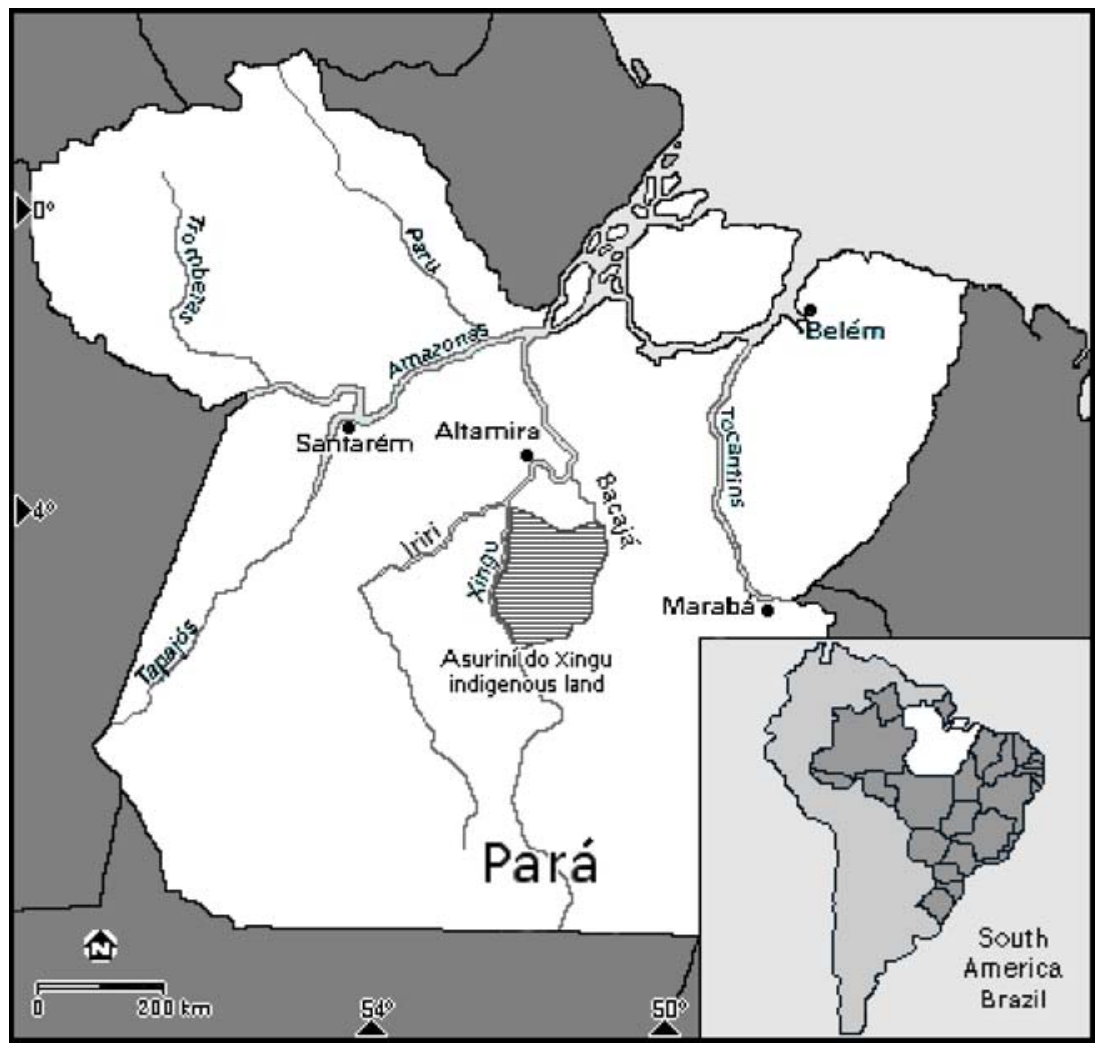

this technology, and the way the Asurini used the space within the village in relation to the activities of production, use, storage and discard of ceramics.

During the first season of fieldwork (October and November 1996), all the village's potters (30 in all), with ages between 15 and 65 years, were interviewedwith the assistance of ten Asurini translators - on the subject of the sequence of vessel production, the vessels' types and uses, and also the ceramic teachinglearning process. The results of these interviews were later tested and revised in comparison with what I observed in the field.

In the months of September-November 1997, and March, April and September 1998, I developed quantitative inventories of ceramics by household, organizing the data by potter and in tables that contained the following information: type of vessel (cooking, serving, transportation, consumption), dimensions (rim diameter, thickness, bottle-neck height, and total vessel height), use (primary, secondary, daily and ritual use), and storage (new and used vessels). Additionally, I collected clay samples from the two deposits explored by the Asurini potters, in order to conduct chemical and mineralogical analyses to understand the clays' performance characteristics and the potters' technological choices.

At the same time, I observed how the daily activities of vessel production, use, storage and discard were conducted in the village (areas of communal and domestic activities and areas of discard). My strategy of research consisted of covering 
predetermined courses in areas of domestic and communal activities, at different hours of the day, during many days of the week, and of describing and photographing the daily activities that were performed in those places. This research was conducted during the months of the dry season (September-November 1997) and those of the rainy season (March and April 1998) in order to explore if the activity areas had different uses depending on the season. In the area of refuse discard, my observations were conducted in a less systematic way. In my last season of fieldwork (September 1998), I recorded and photographed the places that served as the village's areas of discard and collected random ceramic material from some of the middens.

\section{The Asurini do Xingu}

The first information about Asurini do Xingu goes back to the nineteenth century, but they were not officially contacted prior to 1971 by FUNAI (Fundação Nacional do Índio-Indigenous National Foundation, the official organization responsible for the indigenous of Brazil). The Asurini have a history of conflict and dramatic episodes of depopulation. When they were first contacted in the 1970s, their number was already in decline as a result of conflicts with other Indian groups, but they were soon to confront a more devastating enemy - the diseases transmitted by the nonIndians (e.g., missionaries, government employees, wood traders, land grabbers, and colonists). It is estimated that, in the 1930s, the Asurini consisted of only 150 individuals. In the 1970 s, when they were officially contacted, this number had been reduced by approximately $40 \%$, as a result of flu and malaria epidemics, tuberculosis and unreliable medical assistance (Arnaud 1983: pp. 353-354; Müller 1990: pp. 4548; Ribeiro 1982: pp. 23-30). In the early 1980s, the situation was even more alarming, since their number had been reduced to no more than 52 individuals (Müller 1987).

Other than the incidence of diseases, a low birth rate has also contributed to this demographic situation. This could be explained by the population control mechanisms found among the Asurini even before the contact, which include enemy attacks, marriage and procreation rules and ritual performances (Müller 1984/85: pp. 97-100). Attacks from indigenous groups resulted in abduction of children or their abandonment by their parents, who were forced to make an unexpected escape. Marriage and procreation rules also had an influence on demography, since they determined who would marry who (young women with mature men and vice-versa), the number of sons (two per nuclear family), and the adequate age for the women to become mothers (20-25 years). Shamanism interfered with population growth because sexual abstinence was required during ritual performances from those who took part (Müller 1990: pp. 48-49). Nowadays, marriage and procreation rules are not so rigid, and individuals of the same age can marry and have more than two sons per nuclear family. This is the main reason behind the recent population increase among the Asurini. From the 1980s onwards, as a result of increasing number of births in the village and a better life expectancy within parts of their population, the demographic situation started to recover. In November, 2006 - the last time I visited the villagethere were 128 individuals, including children and adults, divided into 21 nuclear 
families that constituted 16 households. So, despite the problems faced by the Asurini, both internal and external, they have made it into the twenty-first century and their numbers, at least for the time being, have been increasing.

The Asurini are a pottery-producing population whose subsistence is based on agriculture, hunting, fishing and gathering natural resources. Their main agricultural products are corn and manioc, both consumed in the form of stew or flour. Hunting is predominantly a man's work, and it is now done with guns and traps. The animals they hunt the most are deer (Mazama americana), peccary (Tayassu pecari), tapir (Tapirus terrestris), jaboti (Geochelone carbonarea) and tracaja (Podocnemis unifiis), and also some birds like mutum (Crax fasciolata) and jacu (Penelope jacquacu). For gathering, the Asurini prefer the Brazil-nut (Bertollethia excelsa), which is a local nut, and the diverse species of coconuts from the native palm trees. ${ }^{1}$

Agriculture is mostly a woman's task, from planting to harvesting. The men sometimes help them in the planting and harvesting, but their major task is to prepare the field with the slash and burn technique. However, men and women participate equally in the fishing with traps or hook and nylon line.

The women are primarily responsible for the processing of resources and the preparation of food. Yet, the men will assist them with tasks such as the manufacture of manioc flour, the butchering of big game (e.g., deer or tapir), or the procurement of wood for the cooking fire. The Asurini like cooked food in the form of stew or soup made with different meat often eaten with manioc flour. They also like meat grilled directly over a moquem (wood grill) or wrapped - in the case of fish - with banana leaves. Fruits are eaten in their natural form, and in the case of nuts or coconuts, they can be mixed into the stews and cooked meals. The Asurini consume some industrialized products, too, such as sugar, wheat flour, pasta, rice, coffee, soy oil, salt and powdered milk.

All of the resources obtained during subsistence activities, as well as industrialized products, are shared on a regular basis with the members of the domestic group through daily collective meals. Members of other domestic groups can also be invited to share these meals when there are mutual tasks that must be met, for example, building a house, clearing the forest to make a place for a garden, or felling a tree to build a canoe.

To the Asurini, the domestic group is the basic unit within the social structure. It is a production and consumption unit whose members cooperate in order to execute the different tasks related to obtaining and processing resources. The women are the organizers of this economic and social unit, being "the basic unit of production in the Asurini society", while the men are responsible for the "circulation of the produced wealth" (Müller 1990: pp. 64-84).

The same relationship between genders found in subsistence activities can also be found in the ritual sphere and the production of material culture. In the maraka-a complex therapeutic and propitiatory ritual-the men carry out shamanistic performances and capture the ynga (the vital energy) and the moynga (medicine) transmitted from the supernatural to the humans. In the ture-a complex ritual where the rites associated with war, death and youth initiation are conducted - the women assume the role of the shaman and transmit the ynga to the tattooed warrior. All

\footnotetext{
${ }^{1}$ More complete data on the vegetal subsistence of the Asurini can be found in Balée (1988, 1989a, b, 1994a, b).
} 
ritual performances are based on the association between men and women. Therefore, in the ture, while the men play the flutes, the women dance; and, likewise, during the maraka, while the shaman sing, the women dance and make sounds to balance the shaman's song. Finally, if during the maraka the men are the shaman responsible for transmitting the ynga and the moynga to the ill, they transmit it through the pottery vessels and the stew, which are women's products (Müller 1987, 1990).

In the production of material culture, which takes a major part of both genders' daily time, the division and cooperation between men and women is established from the moment the raw materials are obtained to the manufacture and use of the artifacts.

The women's responsibilities are to produce pottery vessels (for daily and ritual use) and body ornaments made with cotton strings, to weave the cotton, and to paint the bodies. The men are in charge of production of body ornaments made of palm tree coconuts, teeth, bones and feathers; and also the string-making with vegetal fibers, as well as the construction of wooden implements, weapons, weavings, ritual objects and the communal house (tavyva).

During the production of these objects, men and women establish cooperative strategies. In the manufacture of pottery vessels, for example, it is very common for the men to help with the transport of clay, the collection of the mineral raw material that will be used for painting, and the gathering of fuel for the fire. Women provide the raw material (cotton strings) for the men to produce their bows, arrows, necklaces, and many other objects that require ties that use this type of fiber. Furthermore, many of the objects produced by men are used by females and vice versa.

\section{The Pottery of the Asurini do Xingu}

Within the Asurini, pottery is an essential item in preparation of daily food and ritual performance, in addition to being one of their primary supports for graphic art, expressing fundamental principles of this population's world view (Müller 1987, 1990, 1992; Vidal and Müller 1986). Furthermore, it possesses a wide variety of forms and decorations, and it is carefully produced using an extremely detailed operation sequence.

\section{Vessel Types}

Based on the research of ethnologists who have previously worked with this population (e.g., Muller 1987, 1990; Ribeiro 1982), an assemblage of seven different vessel types was defined as being used to cook, serve, store and transport foods and liquids. They are, respectively, japepa'i, japepa'i/ja'eniwa, ja'e, ja'ekuia, japu, yawa, and yawi. These previous researchers have also noticed another 13 types that consist of variations of these basic forms and are used for the same purpose (jape'e, japeparakynga; ja'eniwa, ja'ei, kume; japuryna, yajuruwa, yajuruwiho, yawijuruva, indajiwa, pupianekanawa, kavioi, kavioi apua). (Fig. 1).

During my research, I found the same seven basic vessel groups, but I noticed some differences in the secondary types. The following types were found: jape'ei; ja'ekuia; kume, uira, jarati, pekia, uã; kavioi, piriapara, ywua, pupijanekanawa (see 

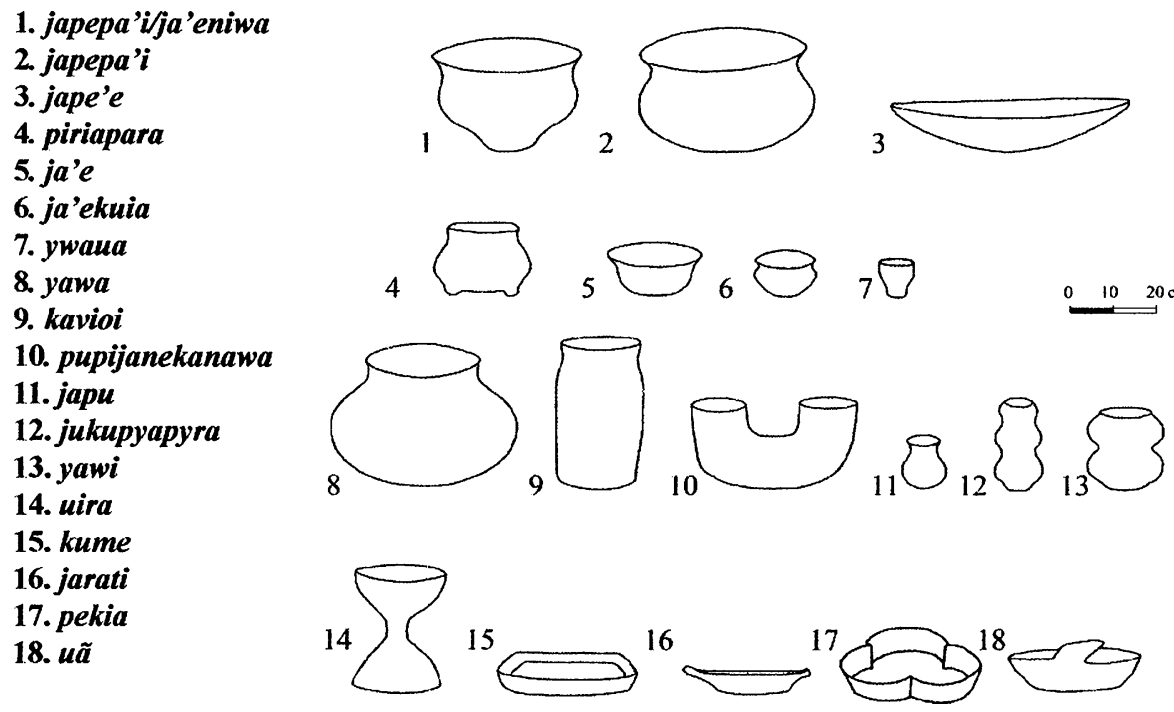

Fig. 1 Asurini do Xingu ceramic typology. This indigenous population has 18 types of vessels grouped into four general classes used in the processing, consumption and storage of food and liquids.

Fig. 1). I have grouped these 19 types into four general classes used in the processing, consumption and storage of food and liquids:

1. Cooking vessels (japepa'i, japepa'i/ja'eniwa, jape'e and jape'ei)

2. Serving vessels (ja'e, ja'ekuia, piriapara and ywua)

3. Consumption vessels (kume, uira, jarati, pekia and uã)

4. Liquid transportation and storage vessels (japu, yawa, yawi, kavioi, jukupyapyra and pupijanekanawa).

\section{Production Process}

The production process of pottery can be divided in a sequence of six basic operations: raw material acquisition, raw material preparation, vessel manufacture, drying, firing, and surface finish. In each one of these more general stages, other more specific steps occur, especially during the vessel manufacture, to which most of the potters referred as "making pans". In this stage of the production, the potters emphasized the particular steps, including the making of coils, overlapping the coils, and the method of forming and scraping the body of the vessel with a paddle gourd.

\section{Selection and Procurement of Raw Material}

In the process of selecting and procurement of raw material, the Asurini potters give prime importance to the clay's plasticity. In addition, they assess the clay after the firing, before announcing it is "good clay" to produce vessels.

During the first stage of my research with the Asurini (1996-1998), the two clay deposits the women explored were close to the margins of the Xingu River, less than two hours walking distance from the village. The deposit closer to the river was in 


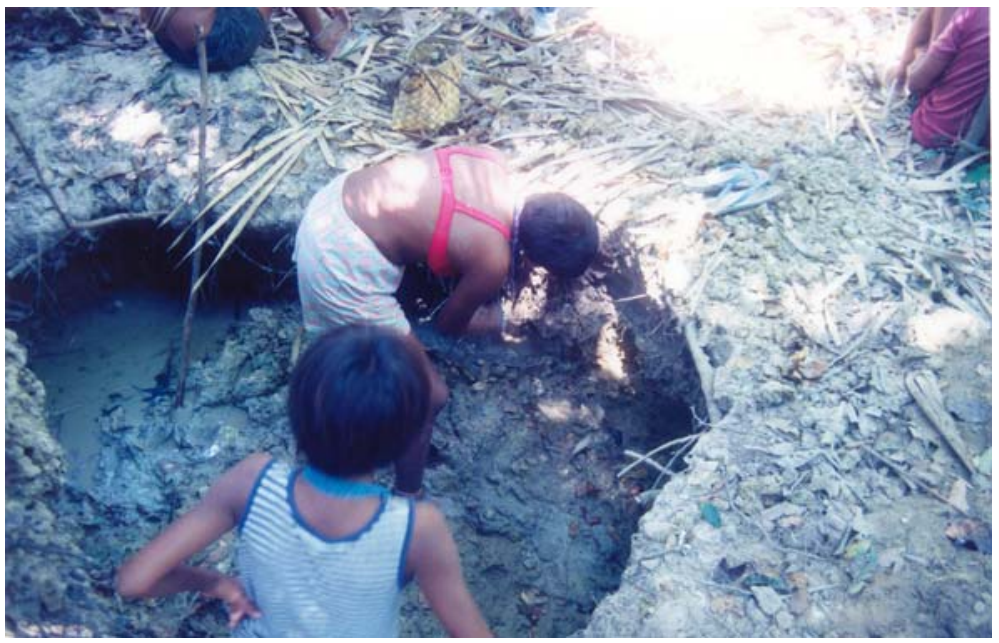

Fig. 2 Asurini potter digging clay from a source near the village $(2 \mathrm{~km})$. Clay is collected from shallow deposits that contain sufficient amounts of sand to obviate the need for adding tempering materials to the clay.

use since the village was occupied, more than ten years earlier. In this deposit, there were two extraction holes: one was $1.50 \times 2.0 \mathrm{~m}$ and about $0.60 \mathrm{~m}$ in depth; the other was $1.50 \times 0.70 \mathrm{~m}$ and $0.50 \mathrm{~m}$ in depth. The "forest" deposit, as the Asurini referred to it, was found later, and it had been explored more intensively in the previous four years. It was not as close to the river and it had just one extraction hole, $1.86 \mathrm{~m}$ in diameter and $1.50 \mathrm{~m}$ deep (Fig. 2).

The mineralogical and granulometric analyses of the clay samples from both deposits revealed important differences in terms of manufacturing performance. The methods of analysis were: X-Ray Diffraction, X-Ray Fluorescence Spectroscopy and Neutron Activation Analysis (Silva et al. 2004; Munita et al. 2005). The oldest deposit, closer to river, is composed of minerals (smectite and illite) ${ }^{2}$ that better absorb and retain the water, giving the clay more plasticity, but, at the same time, make it more likely to break during the firing. The second deposit, on the other hand, provides clay composed of minerals (kaolinite and halloysite) ${ }^{3}$ that give the clay less plasticity, but because of the greater granulometry (large amounts of course sand) there is less breakage during the firing process.

The Asurini had the empirical knowledge of these distinct properties of the deposits, as can be seen in their recognition of the best plasticity within the first

\footnotetext{
${ }^{2}$ Smectite constitutes a group of clays formed from the erosion of rocks rich in minerals such as calcium, magnesium and iron. It presents fine granulometry, very good plasticity, and high degrees of contraction during the drying; in environments with a lot of rain and elevated temperatures it can transform itself into kaolinite. Illite comprises a group of clays similar to the smectite, usuallybeing formed by the alteration of the kaolinites. Its granulometry is fine, its plasticity is good, and it is commonly found in calcarious sediments (Rice 1987: pp. 43-50).

${ }^{3}$ Kaolinite constitutes a group of clays in an advanced degree of weathering, in comparison to the mother rock (for, e.g., granite). This mineral is usually formed in hot and tropical environments, and it is rich in aluminum. Its granulometry is high, its plasticity is good and it has a low contraction during the drying (Rice 1987: pp. 44-47).
} 
explored clay deposit (composed of minerals, smectite and illite), as well as in most of the women's preference to work with it. Concerning the clay's performance during the firing, however, they did not make these distinctions within the deposits.

To remove the clay, the women need to enter the hole with the help of an excavationstick. The woman controls the depth of the digging to be sure that the clay will not become contaminated with an excess of sand, rocks or organic material. After the clay has been removed, she puts it onto a babassu leaf (Orbignya martiana) before placing the clay in a basket to transport it to the village. Once in the village, the clay is stored in baskets or aluminum vessels inside the houses or in attached areas, protected from the weather.

As noted by Lévi-Strauss (1986), in many groups, pottery is always part of mythic narratives and the object of carefulness or forbidden precepts. Usually, the place of clay extraction is considered a dangerous place, inhabited by supernatural beings. Because of this, potters of different cultural groups are usually very careful when they extract clay to avoid infuriating these supernatural entities who think they own the raw material.

This is true among the Asurini, who say the clay belongs to the supernatural beings and its deposits are considered a feminine space that must be avoided by men, who cannot help in the clay extraction. Menstruating or pregnant women should not help in the clay extraction either, since they could damage its properties and the ceramic vessels could break during firing.

Today, the Asurini potters explore the old deposit close to the Xingu River and others located in the Indigenous Reserve area (Silva 2000: pp. 57-58). The "forest" deposit has been abandoned because for them the clay has become too dirty to be used in vessel production. The potters decided this clay was dirty and inadequate to vessel production because, in their own words, those vessels produced with this clay broke more frequently during the firing. They attributed it to the fact that menstruating or pregnant women might have explored the deposit, which would have made it dirty. As indicated by Douglas (1976), different cultural groups have a similar behavior concerning certain substances and altered states of the body, that is, they associate the same notions of danger and impurity. With the Asurini potters, menstruation and pregnancy were held responsible for altered properties of this deposit's clay, making it inappropriate to vessel production.

Finally, it is important to mention that the Asurini potters choose clay deposits whose properties allow them to make the paste without adding temper. When they identify a clay deposit, the first thing they do is to rub it between their fingers and then place it in their mouths to test its plasticity. After that, they produce vessel miniatures to test the clay's performance during the drying and firing processes. It is only after these tests have been done that they will decide if the deposit is adequate to explore. The mineralogical and granulometric analyses conducted with clay samples from the deposits they explored revealed that the clay presented a certain amount of sand that served as a natural temper. This behavior in the selection process has been found in other pottery-producing groups (Longacre 1991: p. 97; Rice 1987: pp. 406-413).

\section{Raw Material Preparation}

The Asurini begin to knead the clay between their fingers while it is still a little wet, making balls that fit in their hands. During the process, they also pick out the rocks 
by hand. Slowly they gather a sufficient amount of clay to produce the vessel they want. Sometimes, when the clay is stored for a long period of time, they break it up with the help of a wooden stick or the bottom part of a metal axe-some use the axe to squeeze the clay when it is still wet. Next, they screen the clay, transforming it into fine sand upon which they put water, so that, afterwards, they can hold it inbetween their hands until it becomes the paste necessary for vessel manufacture. After the clay is kneaded and ready to work it is placed upon a babassu leaf or a wooden support on the ground.

\section{Vessel Manufacture}

The Asurini make their vessels with coils. They begin by putting the clay against a wooden support and with one or both hands produce a coil that will be rolled over their palm in order to make the conical base of the vessel. After that, they go on producing other coils that are added to the base to form the vessel's body (Fig. 3).

When each coil is added, the potters will pinch the joins together and provide the initial smoothing of the vessel's body with their fingers. Additional smoothing with a gourd paddle is done while the vessel is being made. Great care is taken during this step, according to the potters, who state that "the vessel should be as smooth as skin." Each vessel type starts with the same conical form, but during the smoothing process the potters begin to define its final shape according to the function for which it is destined (Figs. 4, 5 and 6).

After defining the form of the vessel, the potters will shape the rim. Since it has to stay very thin, they take little portions of clay between their fingertips and smooth the rim with their saliva-moistened fingers. They use saliva during the whole process of smoothing, whether with their fingers or the gourd paddle. For the Asurini, the female saliva has special properties, and sometimes they spit over their food when it

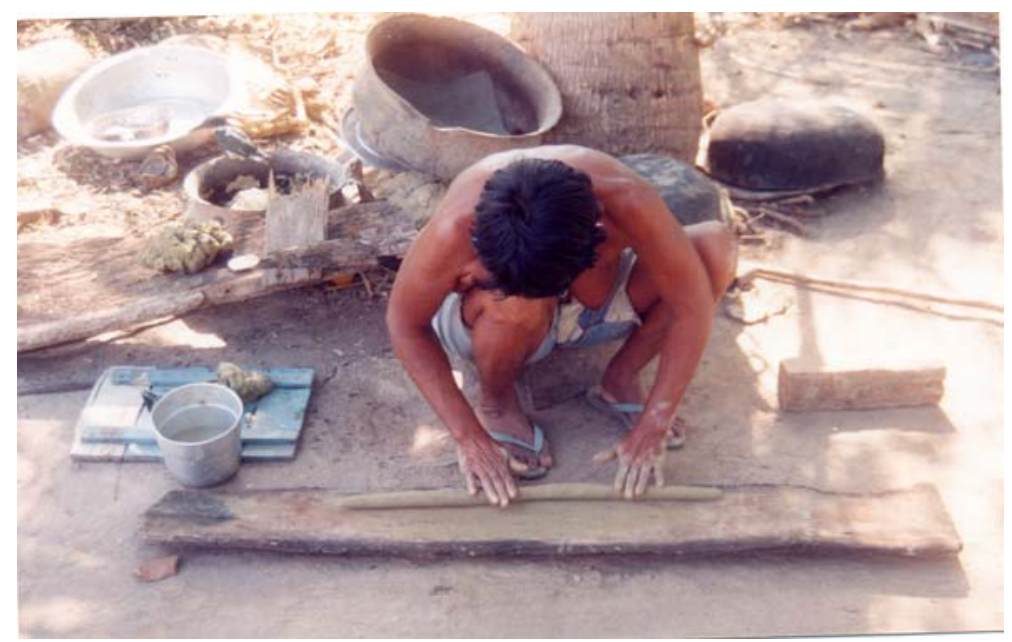

Fig. 3 The Asurini potters make their vessels with coils. They begin by putting the clay against a wooden support and with one or both hands produce a coil. 


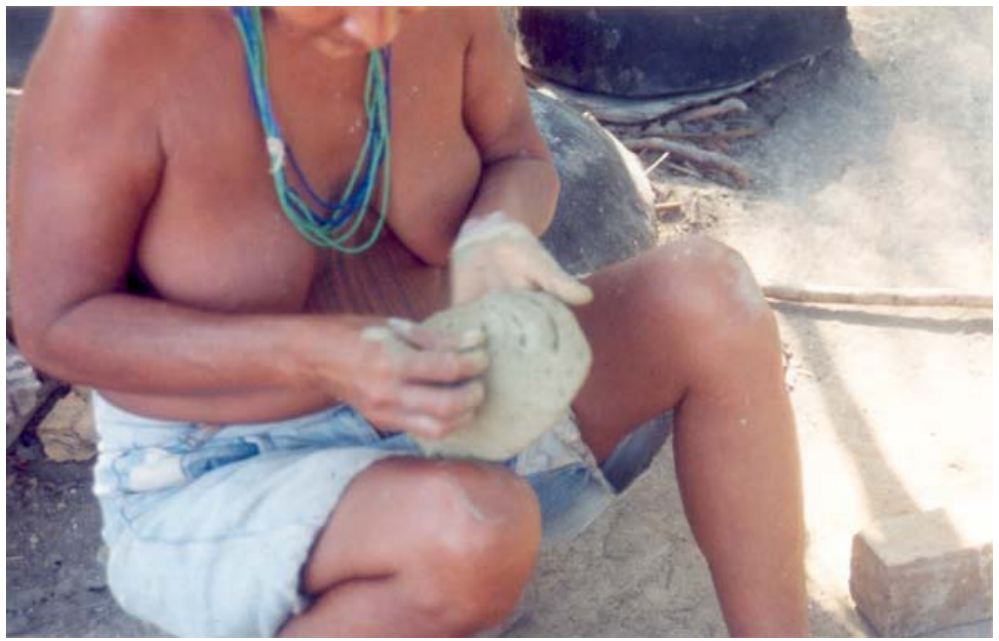

Fig. 4 Asurini potter manufacturing the base of a ceramic vessel. The coil will be rolled over their hand in order to make the conical base of the vessel.

is being prepared. Some of the potters will also avoid eating or drinking during the manufacturing process because they believe it will help the vessel dry.

Finally, it is important to mention that the vessel's manufacturing process is quite slow, and the potters must keep control of the clay's moisture. Any mistake may produce irregular forms or even lead to breakage during the continual drying and firing.

\section{Drying}

After they have produced the vessel it is set aside to dry. The drying time is related to the size of the vessel and climatic conditions. A related factor could be the amount of moisture the potter used during the modeling process. In the rainy season

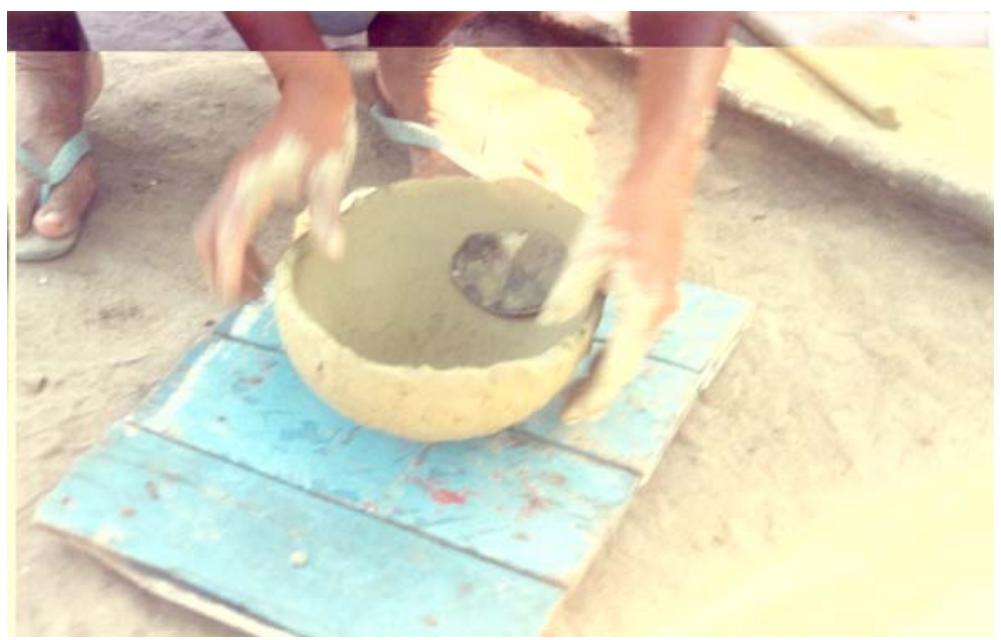

Fig. 5 Asurini potter manufacturing the body of a ceramic vessel using a piece of calabash. 


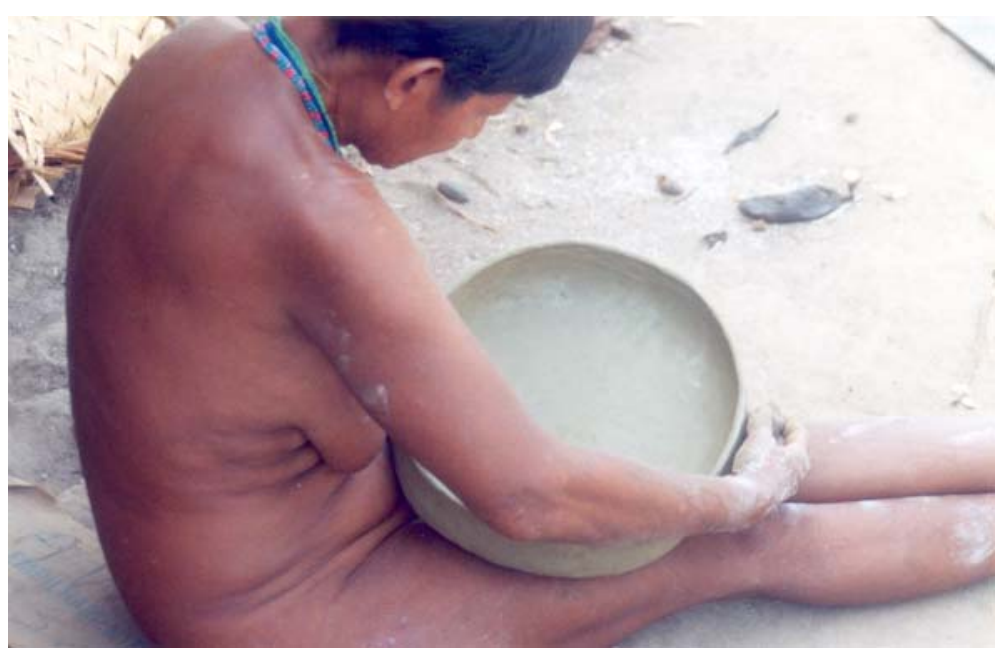

Fig. 6 Asurini potter forming the rim of a ceramic vessel using a coconut (Attalea maripa).

(December-May), one vessel could take from 3-5 days to dry; during the dry season (June-November) it takes 1-3 days to dry, depending on its size.

Vessels are dried differently depending on their form. Yawa, the water transport vessels - with the rim's diameter smaller than that of its body — should be dried with its rim turned up so that its body can expand. It is also necessary to put a cloth over the vessel for it to dry slowly in order to allow the potter to expand its body with the paddle gourd. Vessels used to transport liquids and honey(japu) should dry with their rim faced down, to accentuate the neck and keep the body from expanding too much. The jape' $e$ - used to roast flour-should dry in the same place where it was made, since its form could be easily damaged if moved. All other vessels can be dried with their bottom faced up or down.

While the vessels dry, the potters go on improving and smoothing the external and internal faces with the help of an inajá palm coconut (Attalea maripa) or a small cobble. They rub the coconut or cobble on the vessel's surface while the clay is hardening.

During this stage, they also repair the small fractures that appeared during drying. This care with the vessels' smoothing makes the surfaces denser, less porous and more resistant to wear and tear. Some potters say that during the smoothing with the coconut or stone they are able to know when the pots are ready for the final drying.

\section{Final Drying}

When the vessel is dry, they put it close to the fire for the final stage of drying. They leave the vessel close to the fire until it becomes black, approximately half a day. They frequently make use of the same fire for cooking. The jape'e is positioned with its base over the fire, and the other vessels are put with their mouths or sides turned towards the fire. The vessel is constantly repositioned in front of the fire so that its entire surface becomes blackened (Fig. 7). 


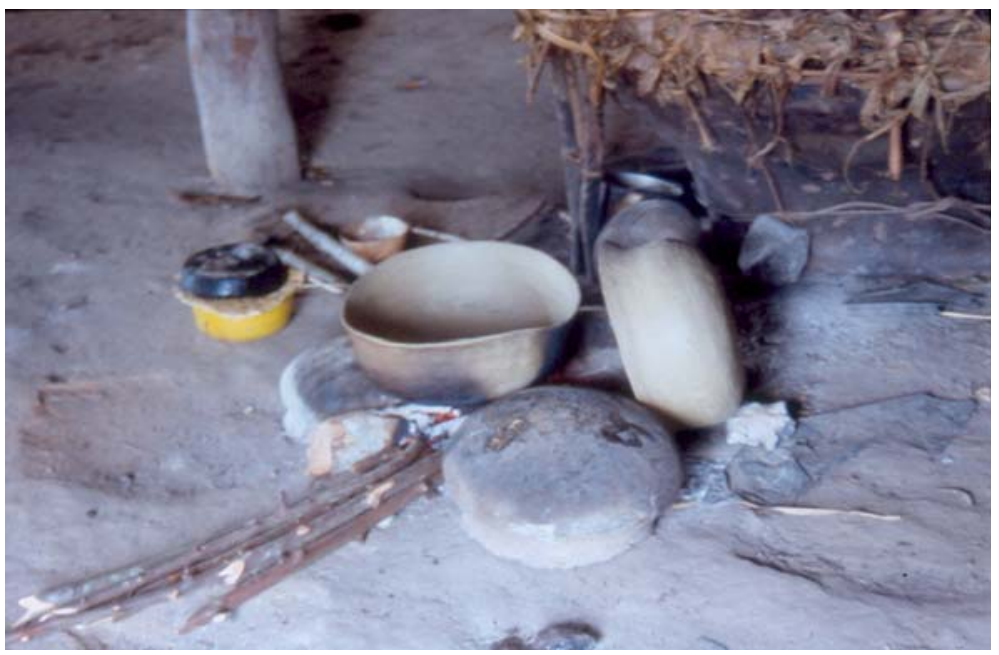

Fig. 7 The final drying of a ceramic vessel. When the vessel is dry, the Asurini potter put it close to the fire for the final stage of drying.

\section{Firing}

At the end of the morning, or at the end of the day, after the vessel has become black from the fire, the potters will start the final firing. They say the vessel should be fired on the same day, because if it becomes too cold it could break when it is put into the "big fire". They certainly know by practice that if the vessel grows cold the humidity in the air will hydrate it again, and that will make it susceptible to breakage during the firing.

The process of firing is relatively simple. They make a circle with bricks, fired clay blocks, stones and broken vessels, and fill the middle with ashes. Each vessel is put on this minimal structure with their mouths turned upwards or to the side. They then cover the vessels with dry tree leaves or bark from the babassu palm. In the absence of babassu, the alternative is to use sucupira (Enterolobium schomburgki), castanha-do-pará (Bertollethia excelsa), cutite (Pouteria sp.), jarana-mirim (Lecythes lurida) and matamatá (Eschweleira bracteosa) (Figs. 8 and 9).

I witnessed 13 firings and found that they varied in time from 30 to $50 \mathrm{~min}$, from the moment the vessels are all covered until the flames are no longer visible. After 10-15 min, however, the flames in the firing cone reach its peak, and they are visible on its top. I inserted 10 pyrometric cones into the firings, in which the maximum average temperatures were between 635 and $747^{\circ} \mathrm{C}$. It was only when more than one vessel (a maximum of 6) were fired together in big hearths (approximately $50 \mathrm{~cm}$ high) that the temperature reached up to $804^{\circ} \mathrm{C}$.

During the next few minutes, the flames become no longer visible. The potters refer to this production stage, when the flames are visible, as the "pretty firing." For them, only a few tree species produce an adequate firing. A well-done firing presumes that the vessels should not present any cracks, and the surface should become completely light and clear. This is so important that some women fire their 


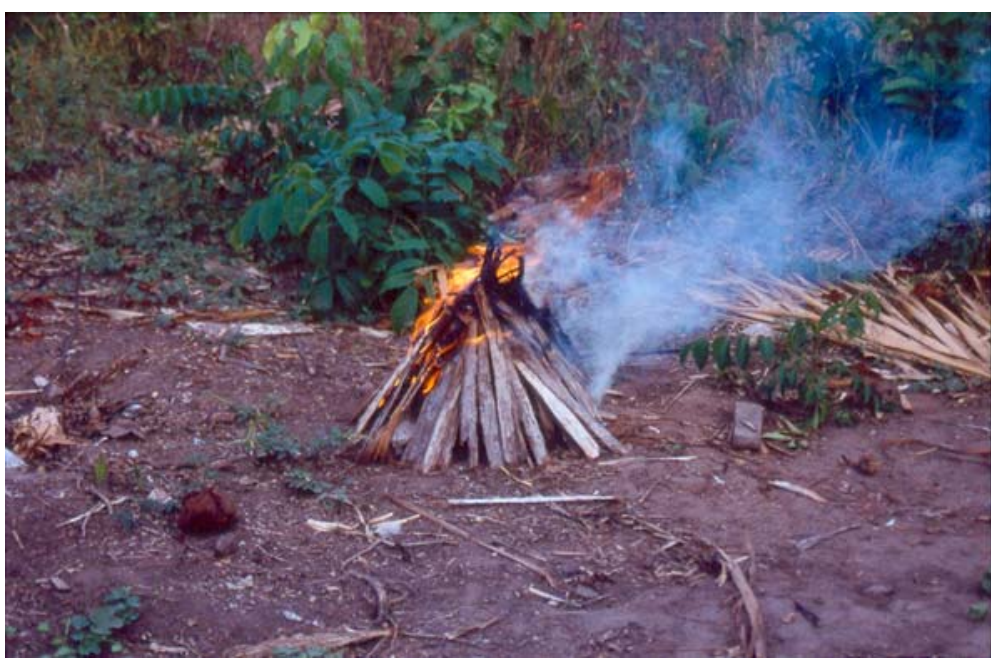

Fig. 8 The firing process of a ceramic vessel. Each vessel is put on this minimal structure with their mouths turned upwards or to the side. After this procedure the vessel is covered with bark from the babassu palm (Orbignya martiana) to burn.

vessels again because they present dark stains (fire clouds) on the surface, and for them they had not had a "pretty firing."

This expression is also used in other daily situations among the Asurini. Fire has other important roles in, for example, garden burning or when a tree trunk is burned to be turned into a canoe. The firing has this aesthetic connotation, and the fire, quoting Müller (1990: p. 151), is perceived by the Asurini as a transforming element that was incorporated in their mythology through the women. With pottery, it is the fire that transforms the clay from raw material into a cultural object. It is an essential element in the transformation of food and in rituals, since the smoke of the shaman's cigars is an important element of contact with the supernatural.

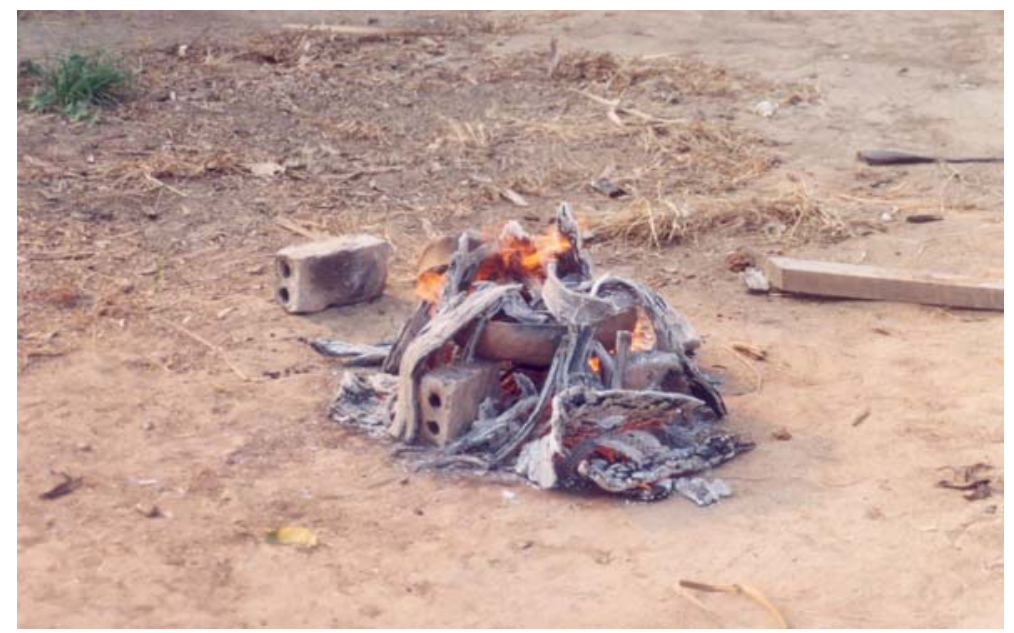

Fig. 9 The final steps of the firing process of a ceramic vessel. 
Firing is a critical stage in the process of vessel manufacture, since all of the previous work could have been in vain if the vessel does not "fire pretty." It can break or cracks may appear. To avoid these problems, the potters take precautions in obtaining clay, as well as during the vessel's manufacture.

As a rule, one could characterize the Asurini vessels as low fired, which has implications for the ceramic micro-structure, porosity and hardness. To counteract these less desirable technical attributes, the potters not only take great care to smooth and polish the surfaces, but they also add vegetal substances (resins) on the internal and external surfaces after firing.

\section{Surface Treatment}

After the vessel has cooled, the women start to paint its external surface. With a piece of cotton they spread yellow pigment over the vessel's surface to create the base coat of paint.

Next, they begin to paint the designs with the black and red pigments. To apply them they use three types of brushes: Mutum (Crax fasciolata) bird feather for the thin lines, and a palm tree stick and the branch from a legume for the thick lines.

The yellow and red pigments are obtained from oxidized iron-based minerals, and the black pigment from minerals rich in magnesium. The women grind these materials on top of a stone support that, after a while, will have a rounded concavity on its upper surface.

The painting of the vessels requires a lot of technical skill, and it is also the place where the potter's creativity appears the most. The Asurini graphic art is very rich, and it grows from a structural pattern called tayngava, which is a supernatural entity represented basically by a human being in a geometric form (see Müller 1990: p. 243). Almost all the painted motifs are a recombination of this structural pattern, and each one receives a different name (Fig. 10).

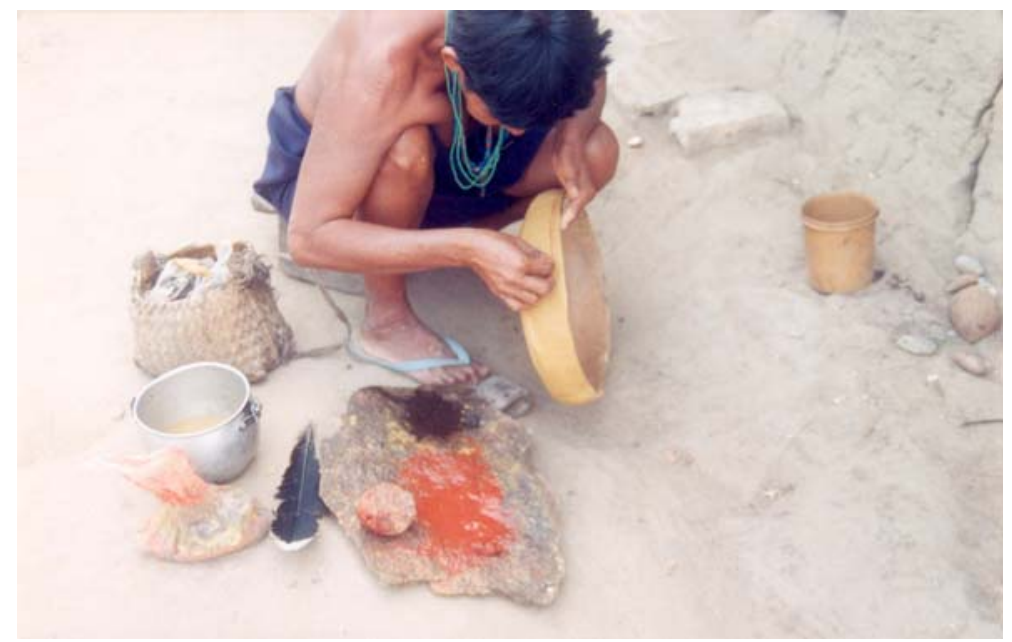

Fig. 10 Asurini potter painting a ceramic vessel using mineral pigments and a mutum (Crax fasciolata) feather. 
When the vessels have been painted, the potters apply a jatobá tree (Hymenaea courbaril) resin called jutaika on their external surface. After cleaning the external part of the resin agglomerate, they attach it to a small two-pronged pitchfork. The potters warm the cooking pot and go on passing the resin over the surface, which melts and adheres to it. Their purpose is to apply a very thin layer of resin, which will show a good surface finish and demonstrate the potter's skill. While the potter spreads the resin over the surface, she smoothes it with a paddle made out of palm tree rachis. During the time it takes her to apply the resin - an activity that can take up to three hours - she should not eat, drink, urinate or defecate. For them, this could make the resin harden, and then it would not disperse with the necessary perfection over the vessel's surface. Usually, they prefer to apply the resin in the morning, since it is a more pleasant time to be in front of the fire. To avoid excessive heat on their faces, they generally put a potsherd in the direction of the flame (Figs. 11 and 12).

When this stage is concluded, they apply another type of resin on the internal part of the vessel so that they can make it impermeable to liquids. With the unpainted cooking vessels, the resin is applied on the external surface too. They extract this resin from a tree bark known as tityva (Inga. They scrape the bark to take away the best fibers, those that hold the most resin. To apply the resin they simply scrub the surface with the softened bark as if it were a sponge.

\section{The Spatial Context of the Ceramic Production}

With the exception of clay procurement, all stages of production occur within the village, in the same places where many other activities are taking place. Usually, the women prepare the raw material outside their houses, a place they call ukara. The vessels' manufacture, however, can take place both in the external areas as well as in the attached structures that are often used as cooking places. The vessel painting stages and the resins' application can also occur in these external areas and also on the attached structures. The jatobá resin application is usually done at the same place

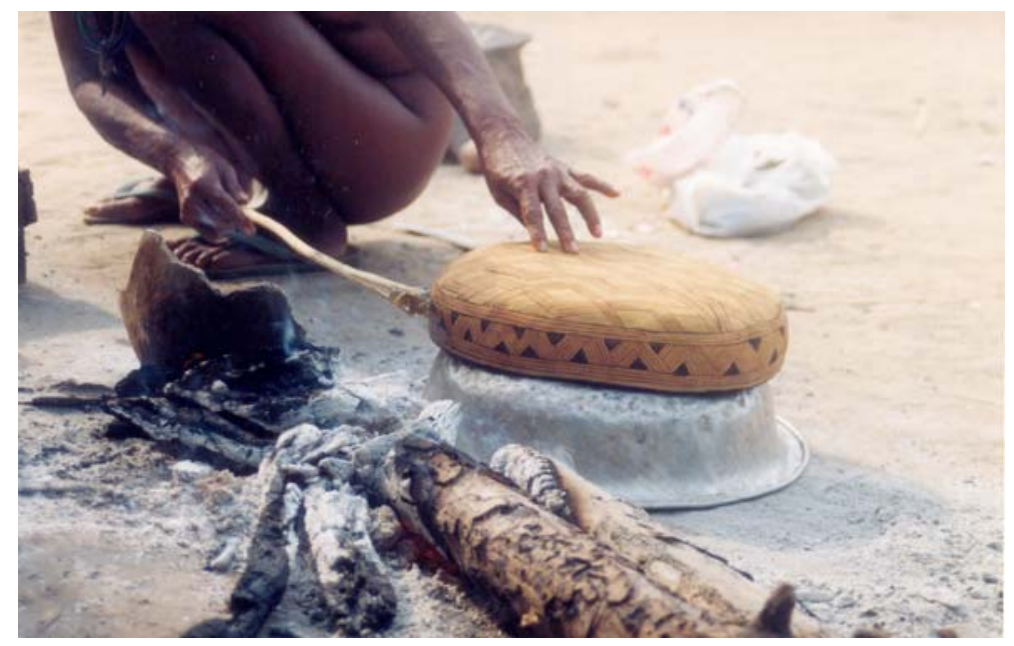

Fig. 11 Asurini potter applying jatobá (Hymenaea courbaril) resin layer on the vessel external surface. 


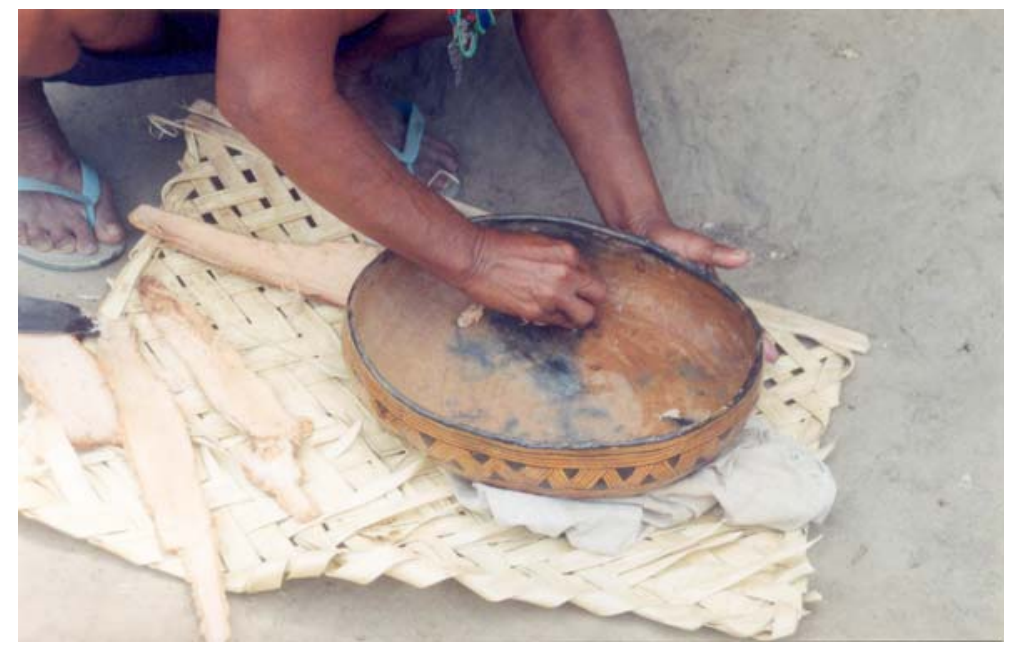

Fig. 12 Asurini potter applying titiva (Inga sp.) resin layer in the vessel interior surface.

where the women cook, which means that the same hearth can be used to perform the two activities simultaneously. The vessel's painting can also be done inside the houses, but this depends on the availability of light. All of the raw material and instruments used to manufacture the ceramic are usually stored inside the houses [mineral for painting, jatobá (Hymenaea courbaril) resin and instruments], but they can also be stored outside or in the attached structures (clay). Firing, however, is done outside the house, usually in the external and close areas.

\section{Gender and the Learning Process of Ceramic Production}

Ceramic production is an eminently feminine activity, and the learning process occurs primarily within domestic family groups through the transmission of knowledge from older women (grandmother, mother, aunt) to the younger ones. The men rarely get involved in this process, and when they are questioned about the subject their answer is often "this is women's thing." They only participate in some of the ancillary tasks, such as transporting clay, fetching fuel for the firing and collecting pigments. This relation the women have with the ceramic vessels is seen not only in the daily activities, but also in the Asurini mythology related to the processing of food.

The Asurini produce pots mostly during the corn harvest, which is in the rainy season (November-May). The frequency of production increases at this time because, as they say, "the corn does not like old cooking pots." This is the reason why, in all the houses, the women need to make at least one new vessel to cook the corn stew.

Corn is the most important staple, and there are several restrictions in behavior associated with its cultivation and use. My informants observed that those who plant the corn should not execute tasks such as cooking, making fire and flour toasting. In addition, those who plant should avoid mutum (Crax fasciolata), jacu (Penelope jасиаси) and peccary (Tayassu pecari) meat, and they should not have sexual 
relations. Furthermore, the women that are nursing should avoid the planting. These restrictions should be followed so that the corn grows well, "because the corn is like a child, care is needed."

The corn is the basic food in the Asurini diet, and it can be consumed throughout the year in the form of different kinds of stew, in every day meals and also on ritual occasions. Its consumption is intensified during the months of February through April, when it is harvested. At this time, the houses are full of corn and, during most of the day, the women produce and distribute the stew throughout the various houses of the village. They share the stew because corn can be harvested in any swidden by the members of different domestic groups. Consequently, the woman who harvests the corn in a swidden she has not planted must offer the stew to the one who planted the corn. It is important to emphasize that not only is the stew shared, but the ears are also divided between the different domestic units. It is common to observe women returning from their swidden bringing some surplus corn that will be given to a relative or a member of another domestic group.

This reciprocity extends to the work of ceramic vessel production and distribution. I observed women within the same domestic group sharing or lending cooking pots. Frequently, sisters that live in distinct houses produce and lend vessels to one another. A sister-in-law can make and loan vessels to her brother's wife. A young woman, with little pottery skills, can be given vessels by her mother-in-law, the mother of her mother-in-law, or the sister of her mother-in-law; and mothers frequently make vessels for their daughters. Sometimes, a woman may lend vessels to her son's mother-in-law. On ritual occasions, when it is necessary, a woman with a kin relationship with the shaman responsible for the ritual will loan her the big japepa' $i$ type cooking pot.

These examples, related to the harvest, the processing of corn and the production and exchange of ceramic vessels exemplify the women's importance in the domestic group's subsistence activities. The production and harvest of crop products, the processing and distribution of food and the manufacture of ceramic vessels are all in the feminine domain. Despite the work that men do in preparing the field and harvesting the crops, cultivation is predominantly a woman's responsibility among the Asurini. The women go to the fields every day with their domestic group and spend, depending on how distant the crop is from the village, an average of three hours a day on this activity. The major part of the women's daily tasks is related to activities of production, food processing and the manufacture of material items related to these activities.

Within the Asurini, the woman is responsible for producing the food in her domestic group, and her specialization in pottery activity is intrinsically related to this social role. The japepa ' $i$ ceramic vessel produced and used by the women is the "symbol of food," and it is an artifact of the feminine domain.

The learning process of pottery making starts early in life, and, in my different visits to the village through the years, I witnessed girls and less skilled young women being trained by the older women. Learning the process of forming the vessel body is one of the hardest stages, and the novice has to produce many vessel miniatures, performing all stages of vessel production, including firing and painting. It is difficult for the young potters to master the stern rules associated with the Asurini forms. It is easy to identify pots made by inexperienced potters - the vessel 
body is often poorly made or the smoothing of the surface is too rough, the rim is very frequently irregular and the resin was not well applied, leading to small mistakes and rough patches.

From what I could observe, the learning process happens through visualization and manipulation of the material. The miniature seems to be the most common didactic tool, and teaching with miniatures is also used with other crafts, such as making the sleeping hammocks. As with other ceramist populations, the teaching of vessel production is extremely controlled, and it requires constant verbalization and demonstration from the instructors relating to the techniques, as well as on the results to be reached in each one of the productive stages. There is an enormous "concern with the technique excellence" (Bunzel 1972: p. 60) during the teaching process.

But it is not only the ceramic learning process that is time-consuming, since the domain of the vessels' formal classification is also complex. Sometimes, the younger women find it difficult to identify the name of a certain vessel and they need to consult the older ones for advice (Fig. 13).

In addition, it is also necessary for them to know how to select and process the raw material and how to manufacture their own working instruments. One stage of production that requires experience, for example, is the moistening of the clay to make it workable. If the clay gets too moist, the coils will stick in their hands, production will be much more difficult and irregularities will be found in the vessel's form.

In conclusion, the ceramic learning process is long and complex, and, for this reason, it is mostly the older women who master this knowledge. Child rearing gets in the way of the learning process, therefore women are taught the craft very early, before they become mothers. Skill in this activity is reached only with the passing of

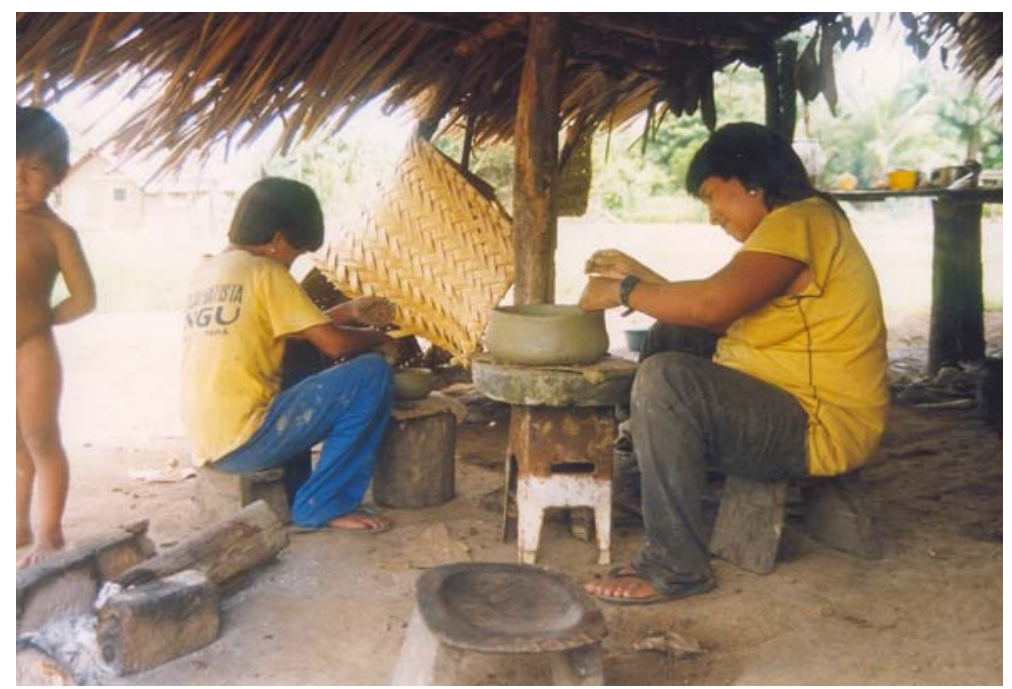

Fig. 13 Mother and daughter manufacturing ceramic vessels. Ceamic production is an eminently feminine activity and the learning process occurs primarily within domestic family groups through the transmission of knowledge from older women (grandmother, mother, aunt) to the younger ones. 
years, and it is usually the older women, around 50 years of age or more, who are considered the best potters in the village.

\section{Technological Tradition and Individual Creativity}

As with other indigenous societies, the Asurini ceramic production results from a dynamic relation between precepts of the technological tradition and the potters' individual creativity. In order to explore aspects of this relation, I conducted a metrical study of both the existing vessels in the Asurini village (in 1998) and those collected earlier, which are stored at the indigenous Cultural Center in Altamira.

A total of 323 vessels were measured, and data about each potter and vessel type was registered at the Asurini village and Altamira city. The measurements taken were: total vessel height, neck and bottle-neck height, rim diameter and thickness of the rim wall. The data were analyzed using Variable Correlation and Cluster Analysis, which highlighted groupings based upon the measurements taken. Variable Correlation Analysis and Clusters were analyzed through the SPSS Program. In the first case, existing relations between different variables (height, diameter, thickness) were explored, and dispersion diagrams were created. These indicate the direction of this relation (positive or negative), its form (linear or curvilinear) and its intensitymore or less density of dot clouds surrounding the line (Shennan 1992: pp. 123127). In the second case, we explored the similarities between each one of the ceramic vessels analyzed. The subjacent idea of this statistical analysis technique is that the objects should be similar to each other in different levels, in a way that the results could be represented through dendrograms, or a tree-form diagram that demonstrates the similarity relation within objects and groups of objects. The principle is the grouping of series of vessels that gradually form groups, according to their similarities. On the first levels, vessels with greater similarities group together, and groups are gradually gathered according to more general similarity criteria until all of them are gathered together, forming one unique group (Shennan 1992: p. 215).

In terms of Variable Correlation, vessel types jape'e, japepa'i, ja'e and ja'eniwa were the ones that presented the most significant correlations. The sample sizes for other vessel types were too small for this type of analysis. ${ }^{4}$

As can be seen in Fig. 14, there is a significant correlation between height, thickness and diameter in the jape'e vessel type. This means, simply, that height and wall thickness increase in proportion to the vessel diameter. Similarly, there is a significant correlation for the japepa' $i$ vessel type between bottle-neck height, thickness, vessel height and diameter. In both types, when the size of the vessel increases, wall thickness, the height of the bottle-neck, and the opening of the rim diameter also increases. With the ja'e vessel type, the significant correlations are between the opening of the rim diameter and its height. For the ja'eniwa vessel type, the correlations occur between height, thickness, bottle-neck and diameter. In other words, the size of the vessel increases in conformity with the wall thickness, bottleneck height and opening of the rim diameter.

\footnotetext{
${ }^{4}$ Some vessel types were not numerically significant (2 or 5 vessels) in the total set of the sample, which made the statistic analysis team disregard these vessels during the process of analysis.
} 


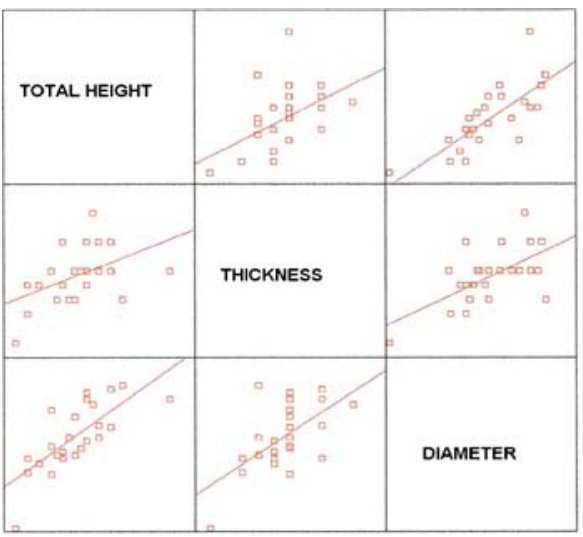

jape'e vessel

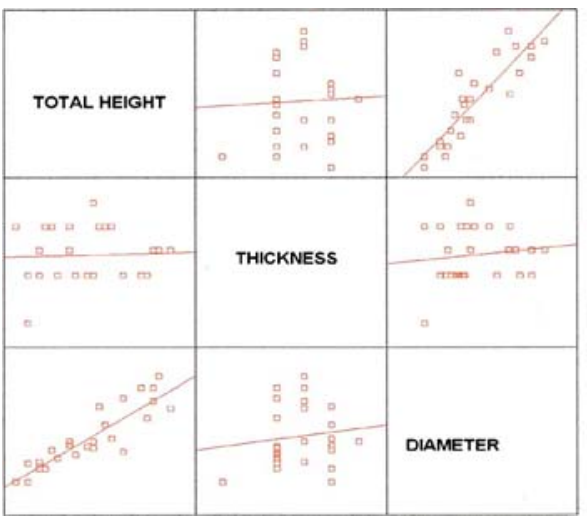

ja'e vessel

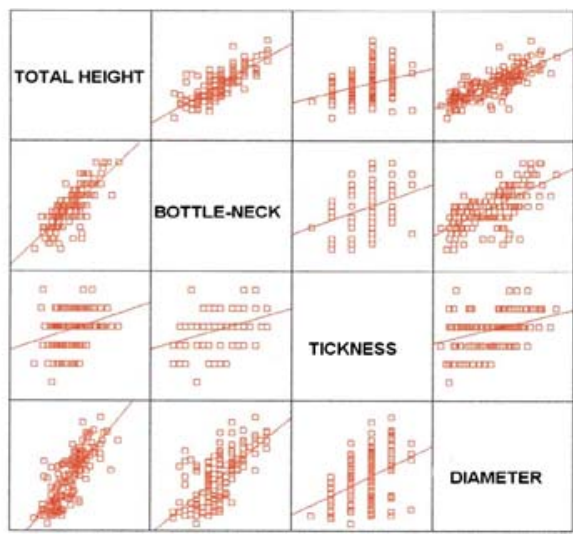

japepa'i vessel

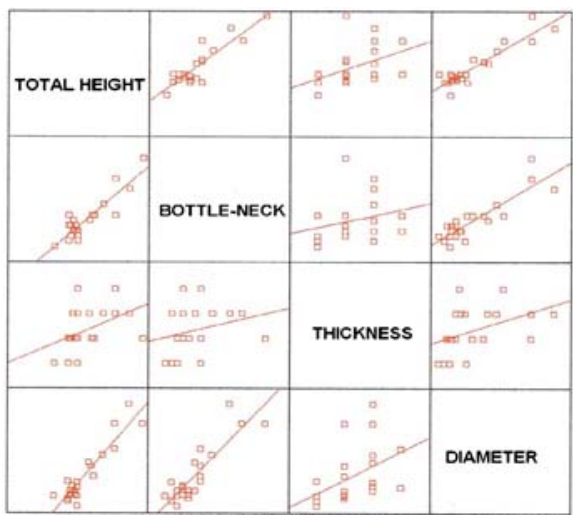

ja'eniwa vessel

Fig. 14 Correlations diagrams of vessel types (jape'e, ja'e, ja'eniwa). The correlations demonstrate that the construction of these vessels follows a pattern that are abided by all of the Asurini potters.

To sum up, these correlations demonstrate that the construction of these vessels follows a pattern and proportionality that are followed by all the Asurini potters. The proportionality between the size of the vessel's opening diameter and its height is very regular, and the tendency, in the specific case of the japepa' $i$ vessel type, is that the vessels become more rounded with an increase in size. One particularly interesting pattern was that the thickness of the vessel walls also followed the proportionality related to its size. For the Asurini, the thinnest vessel walls are the "prettiest ones," and potters who can make thin walls are considered the most skilled. However, the statistical analysis demonstrated that, despite their aesthetic preference, they adapt the wall thickness according to the size of the vessel, obeying the same proportionality rules as with the other variables.

The vessel group analysis (clusters) agreed with the results obtained through the correlation graphics and, at the same time, allowed us to make inferences on the relation between the ceramic patterning and the domestic group. 
Fig. 15 Dendrogram for the jape'e and ja'eniwa vessels. These cluster analyses agreed with the results obtained through the correlations graphics and, at the same time, demonstrate that the Asurini potters, independently of the domestic group they belong to, produced the vessels in a very similar way, presenting a technological patterning.

On the dendrogram reported for the jape'e vessel there are three vessel groups that have many similar characteristics. Our conclusion, from the dendrogram analysis, was that the Asurini potters, independently of the domestic group they belong to, produced the vessels in a very similar way, presenting a technological patterning. The same interpretation is evident from the dendrograms of the $j a$ ' $e$ and ja'eniwa vessel types (Fig. 15). On the dendrogram of the ja'eniwa type, one can observe that the vessel groupings found at the city of Altamira formed a more homogenous group, reinforcing the idea that there is a technological patterning among the Asurini potters, independent of the domestic group.

This pattern is most evident in the dendrogram related to the japepa' $i$ type. One vessel type that did not fit the general pattern was the ywua, a vessel destined exclusively for sale, according to the potters. This vessel type, found only in the collections at the Indigenous Cultural Center in Altamira, had a great deal of metrical variability, unlike what was seen in the pots made for consumption (Fig. 16). It appears that, when they produce vessels for sale, they do not adhere to the same rules of proportionality seen with the vessels they made for their own use.

In sum, the statistical analysis demonstrates that the Asurini potters present a technological patterning not related to the domestic group, but instead to the teaching-learning structure shared by the women of all domestic groups.

These technological rules, however, do not prevent the women from exercising their individual creativity when producing their vessels. All of them said that they could recognize their own vessels from those of the other potters. According to them, the recognizable traces are found on the rims, base and body. This recognition relies on very subtle categories that, many times, are difficult for the potters to verbalize. I could never identify these differences, and even the potters themselves often found it difficult. This is the reason why it is common for them to carefully store their vessels separately, inside their houses or attached structures, so that they would not get mixed up with vessels made by other women of the same domestic group.

But it seems that it is in the vessels' painting that their individuality is more clearly manifested. According to Roe (1995: p. 45), "there is no contradiction between subjective individual creativity and traditional prototypes." Thus, from a determined structure of possibilities offered by the cultural tradition, the Asurini craftswomen can make their individual choices and also transform the production of ceramic objects into "a vehicle of personal experience" (Bunzel 1972: p. 52).

Despite the individual creativity present in the vessels' painting, one can observe a relationship between the motifs employed by the potter and the specific domestic group she belongs to. According to my informants, there are some arrangements of the tayngava (graphic art structural pattern) that some domestic groups employ more than the others. That is to say, although there is a common repertoire of Asurini graphic art motifs, the domestic groups make use of it in a distinctive manner. They also said that there are motifs whose manufacture and naming are restricted to some 

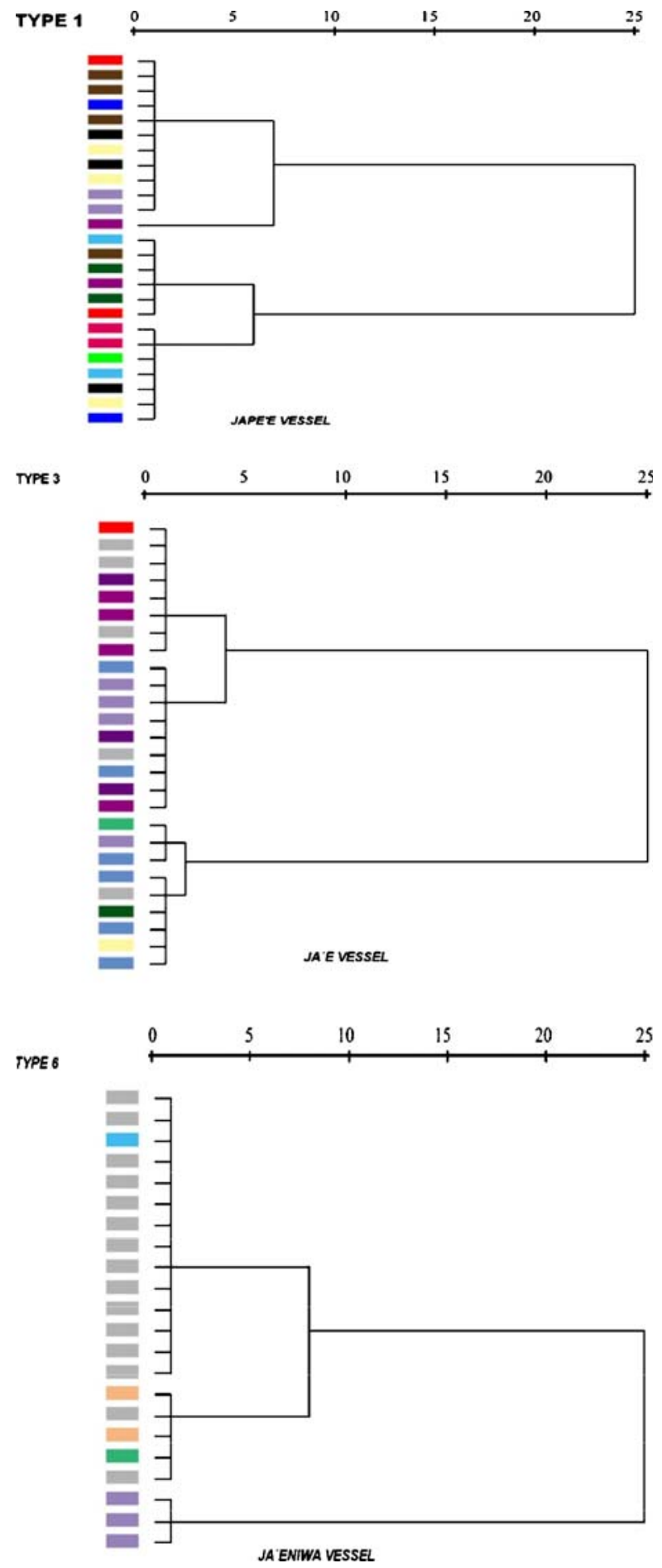


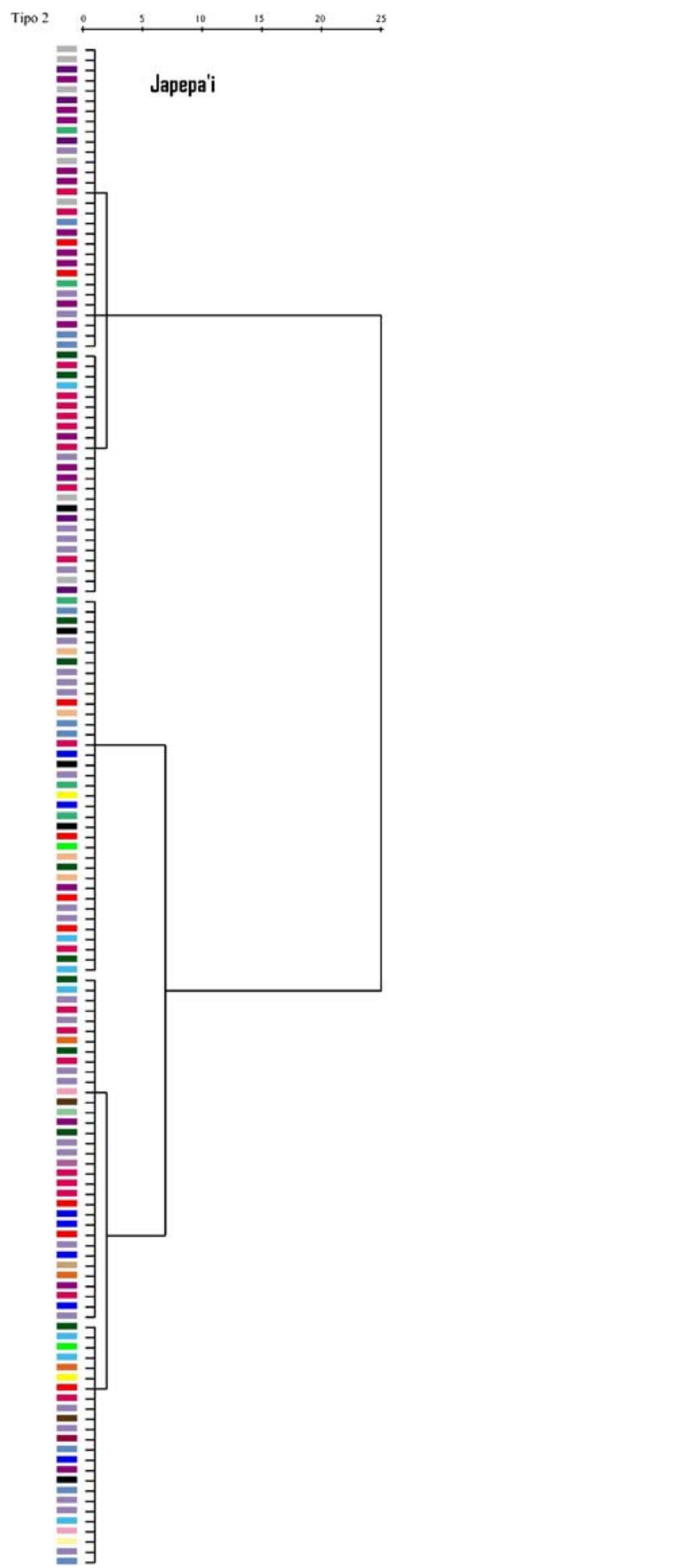




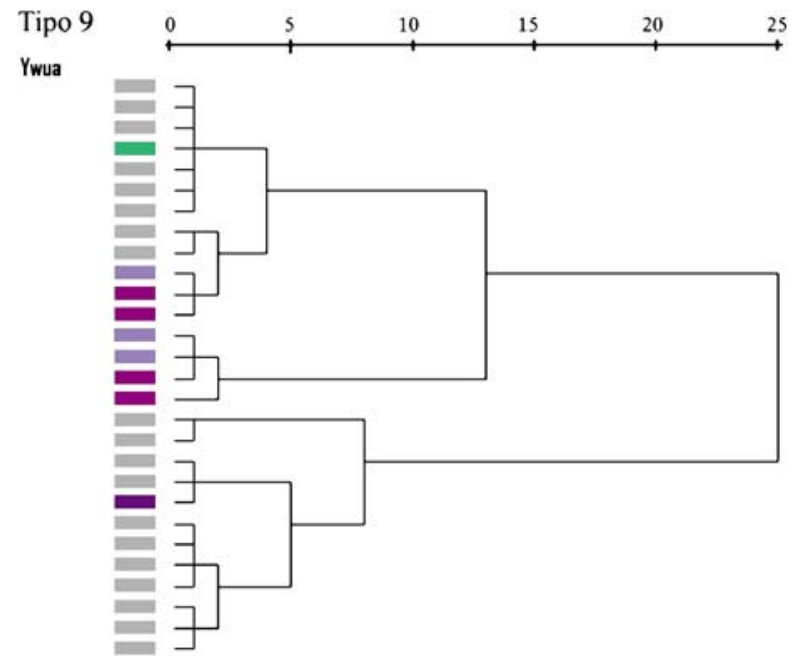

Fig. 16 Dendrogram for the japepa' $i$ and ywua vessels. These clusters analyses demonstrate that the japepa' $i$ vessel is produced in a very similar way by the potters, presenting a technological patterning. The ywua vessel is produced only for sale and does not adhere to the same rules of proportionality seen with the other vessels.

women's knowledge, usually the older ones. But this issue still needs to be explored further, and will be one of my concerns in my future research among the Asurini.

Ceramic Lifecycle within the Asurini do Xingu

Nowadays, the Asurini women have abandoned the traditional usage of most of the ceramic vessels previously used to serve food and store and transport liquids. These have been replaced by several types of industrialized objects such as aluminum pans, plastic jars, plates, cups, bowls and Thermos bottles. Thus, their production has become restricted to vessels to sell to tourists outside the village.

The vessel types that are still used in traditional ways are the japepa' $i$ and the japepa 'i/ja'eniwa, ja'e, jape'e and the jape'ei, used, respectively, to cook and serve the stews (for daily consumption or in rituals), roast the flour and make beijus (thin, crisp, rolled manioc flour pancake). On some occasions, one can observe a woman cooking mutum meat and fish on the japepa' $i$ vessel type, but more often the meat is processed and baked in aluminum pans.

According to my informants, the durability of a japepa' $i$ for cooking is about two or three years, and that of a jape'e is from two to four years. However, this use life is quite variable and could be reduced to mere days depending on different factors: intense usage, children's games, transportation and usage accidents, and failures on the productive process. The women say that the japepa ' $i$ is a less durable vessel than the jape'e, since the former is usually used over the fire. In fact, while this vessel is used to cook practically every day, the jape'e is used only once or twice a week to grate the flour or to make beijus (Fig. 17). 


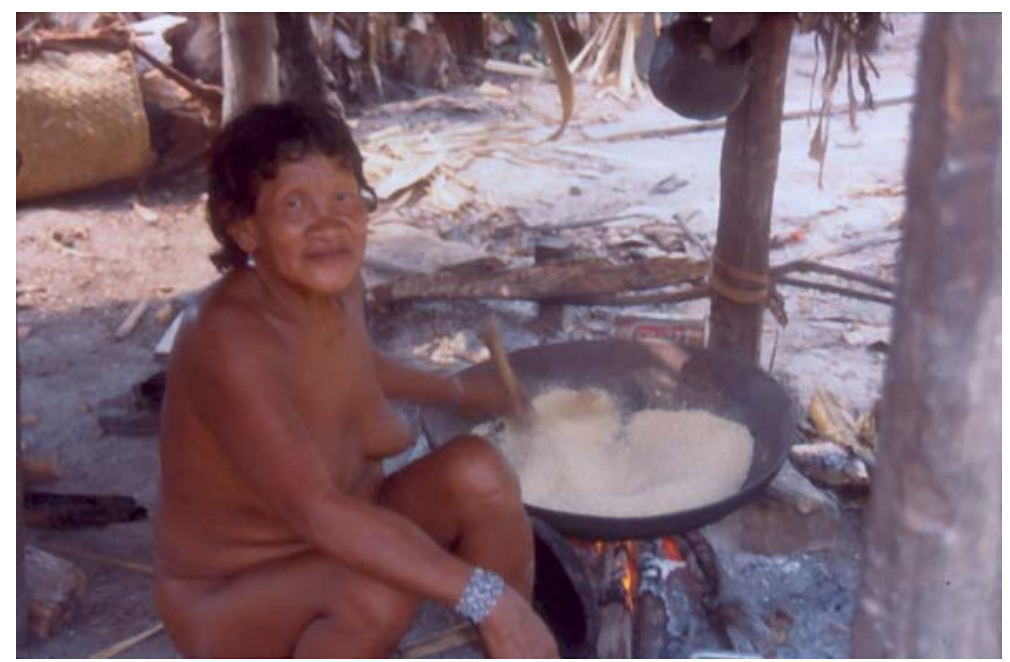

Fig. 17 Asurini woman roasting manioc flower in the jape'e vessel.

It is important to emphasize, however, that even when the vessels are damaged they are reused and acquire a series of other usages on a daily basis. Even the potsherds are recycled - to hold jenipapo (Genipa americana) pigment used on body painting, to serve as a shield on the hearths when the women apply the jatobá resin, or as a vessel support in the firing structures.

The most frequent reuse is when a vessel is used as a pot support in a kitchen fire. Other frequent reuses are the cooking of babassu palm tree oil in a japepa' $i$ type vessel or storing clay and the mahogany bark pigment used to dye cotton fibers, also in a japepa' $i$ type vessel. Cooking and serving pots can also be used to store food products such as corn flour, corn seeds, beads, seeds, instruments, fishing equipment, jatobá resin, charcoal for body painting and cotton; it can also serve as a trashcan.

All of the vessels I saw being used for these purposes were damaged. In the case of the japepa' $i$, it was possible to identify cracks on their bases or walls and breakages on their rims. On other vessel types, the damage was either cracks in the exterior surface or paint peeling.

Frequency of Use, Storage and Discard of Ceramic Vessels at the Asurini Village

From a systematic survey of the frequency for each residence, I determined that each domestic unit had an average of two japepa' $i$ vessels and one jape'e. ${ }^{5}$ The jape' $e$ is usually a lending object between women of the same domestic group, and as a result its occurrence is typically less than that of the japepa' $i$.

Although there are a low number of pots used per domestic unit in the village, the Asurini possess a considerable number of stored vessels inside the houses or attached structures. During one of my stays (September-November 1997), 223

\footnotetext{
${ }^{5}$ There are families who employ five japepa'i and two jape'e vessels, while others employ only one japepa' $i$ and do not even have jape'e vessels.
} 
vessels were counted in the entire village (including pots reserved for sale and those stored for daily use). There were 16 domestic units in the village during this period, and each household had an average of about 14 vessels of various types. The range of vessels per household, however, was quite large, with some domestic units having up to 30 pots, while others had just 2. This wide range does not result from any socio-economic distinction between the different domestic groups; rather, it is because some women preferred commercial pans. Vessel production was quite low then, and during the 90 days of this research visit only 34 vessels were made.

In contrast, during a follow-up fieldwork visit (March-April 1998, the rainy season), the amount of vessels produced was much higher. In the 60 days I remained in the village, 52 japepa' $i, 5$ ja'e and 15 vessels of the jape'e type were produced. Household use of the vessels, however, was not too much different as there was an average of 2 jape'e and 3 japepa' $i$ were in use in each domestic unit. Because of increased production, more new vessels were being stored inside the houses or in attached structures for future use. A total of 287 vessels were inventoried during this visit.

The difference between pots that are in use and in storage is related both to vessel use life and production patterns. As I have already mentioned, everyday use vessels are intensively used, frequently broken, reused and recycled. Damaged vessels are not discarded, and they remain in the village to be reused in a variety of functions. They are often stored in a structure attached to the house.

Ritual and symbolism also influence vessel production and the number of pots in storage. Every year, during the corn cropping season (from February to April), the potters devote themselves to the production of new japepa' $i$ type vessels that will be used to cook corn. As mentioned earlier, corn is an extremely important product within the Asurini diet, and its planting involves a series of ritualized activities. Furthermore, it is during the planting season that the ture rites are initiated, and the corn stew is an important food in this activity.

The ceramic vessels are important to the potters not only because of their daily and ritualistic use, but also because pottery production is an activity related to social issues. The teaching-learning structure of ceramic production bonds the women within the same domestic group, while the lending of vessels reinforces the social reciprocity between different domestic groups. One can say that the women identify themselves with their vessels.

This relation between the potters and their vessels is so important that, when a potter dies, her vessels must be broken and thrown away, even those owned by other people. I asked them why it was done and they answered: "it is so that no one keeps remembering her, missing her." When an Asurini dies, the others are not allowed to pronounce the dead one's name, because they fear his spirit will return from the world of dead to steal the souls of the living; consequently, it is also necessary to destroy everything that reminds them that person. This process is related to the crucial distinction that the Asurini make between the ones who are alive and those who are dead, between those who have the ynga (vital energy) and are humans (complete, living), and those who are spirits or anynga (divided).

Finally, one can understand the maintenance of the ceramic vessels symbolically as the Asurini's means to assert their own world view. Thus, the ceramic vessels are not stored just because they are reusable objects, but also because they are objects 
embedded with symbolic meanings. This way, the ceramic vessels really mark their presence within the village, since we find them and their remains everywhere.

Given this perception of the ceramic vessels, it is interesting to observe that they are often discarded quite randomly. They usually deteriorate in the village and their sherds get scattered through the house interiors, as well as their patios. When the women clean the houses and close areas, these sherds get mixed with other detritus and are taken to the trash areas.

During my stay in the village, I investigated the trash areas and collected surface potsherds. The ceramic remains are usually small, and no entire vessel could be reconstructed. That is, almost the entire vessel is "consumed in the village," leaving a small part to be discarded in a more definitive manner.

\section{Ceramics and the Tauva Ritual}

Among the Asurini, as one can observe, the ceramic production by the women is part of a wider group of activities, and its importance is related not only to the subsistence of the domestic group they belong to, but also to social and ritual life dynamics. In one of my stays in the village (September 1998), I witnessed the performance of the tauva ritual, and it was evident that the ceramic technology is not just an economic activity, but should be understood as a discourse connected to the relations people establish with the material world, with themselves, and between humans and the supernatural world.

\section{The Tauva Rukaia and the Tauva Ritual}

As Müller (1990: p. 91) has described, the tauva ritual is part of the ture ritual complex, which is related to "different institutions, such as the initiation of the young ones, war and death celebration." This ritual takes place between the rainy and the dry seasons, and it begins with the corn harvesting.

The tauva ritual is related to the tauvyma - a mythic character the Asurini identify as the first potter, whose husband was killed by her brother and as a result leaves the human world by throwing herself in the river and being transformed into the supernatural tauva.

The ritual performance takes place on the ceremonial plaza and in the interior of the communal house (tavyva). For many weeks, the women perform many singing and dancing sessions during different hours of the day and night. The ritual is conducted by women shaman who divide themselves between principal and auxiliary shaman. The men dance and perform the ture songs; they play flutes while the women dance. While the women rest between the tauva ritual chanting sessions, the men keep on playing their flutes, and the older ones tell the young men stories of tribal wars they fought in ancient times.

An important activity taking place during the ritual is the production of the great ceramic vessel called tauva rukaia, which is seen as the receptacle or house of the supernatural tauva. This vessel is collectively produced by the women, and its size is around $1.30 \mathrm{~m}$ in height and $1.20 \mathrm{~m}$ in diameter. Its function is only ritual, and during one stage of the ritual cycle it is used in the rite of passage of the young men. After they have jumped over the pot they assume the social status of young warriors. 


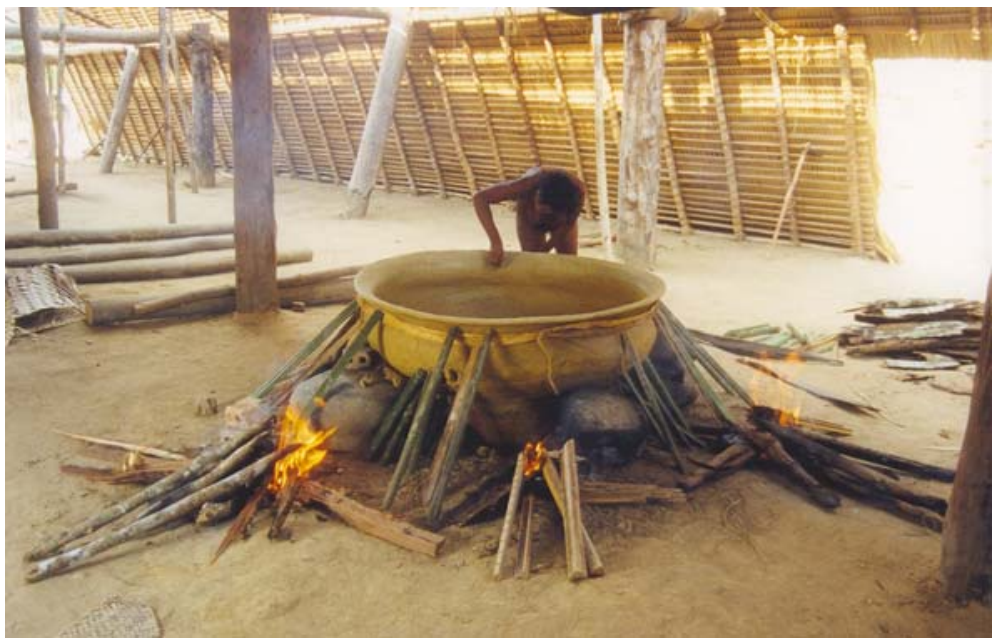

Fig. 18 Final drying of the tauva rukaia ritual vessel.

The vessel is kept inside the center of the communal house (tavyva), next to the sepultures of the dead (Fig. 18).

The tauva ritual is guided and performed by the women, but the theme they sing is the war and the warriors. It is also the moment to cry their dead, much as the tauvyma character has done. Furthermore, the ritual also serves to remember the warriors and to purify them from the enemies' blood.

\section{Discussion of Artifact Variability}

\section{Causes and Significance of Artifact Variability}

Understanding the causes and the significance of artifact variability in the archaeological record has been one of the most important concerns of the archaeologists. One way to approach this issue is to consider the archaeological record in terms of four dimensions of variability: formal, quantitative, spatial and relational. Each one of these dimensions is subject to different formation processes that can be identified only when one considers the artifacts' history or, in other words, all the operational sequences and activities they were submitted to in both the systemic and archaeological contexts (Schiffer 1983, 1987; Skibo and Schiffer 2001). Thus, in this section, I will review Asurini ceramic production, use, storage and discard in the context of these four dimensions of artifact variability.

\section{Relationship Between Technological Choices and Formal Variability}

Formal variability is related to the physical properties of an artifact, and its analysis should take into account aspects such as size, thickness, weight, depth, texture, color, consistency and its formal shape. According to Schiffer and Skibo (1997), the formal variability of artifacts is the result of the technological choices made by the 
craftsperson during the production process. These are motivated by the artifact's performance, the knowledge and experience of the craftsperson, as well as the different situational factors. ${ }^{6}$ In this sense, aspects such as the physical-chemical characteristics of the raw material sources, the manufacturing procedures, the mechanisms of transportation and distribution of the artifacts, their use, reuse, patterns of storage and discard, the individual differences of technological knowledge, and the teaching-learning structure are all elements that should be considered. At the same time, authors such as Lemonnier (1993), Mahias (1993) and van der Leeuw (1993) emphasize the importance of considering the social organization and representations as motivating elements for the technological choices.

Among the Asurini, the formal variability of pottery is the result of the potter's technological choices, from the selection of raw material to the artifacts' final surface treatment. These choices can be made in a general manner by the group or by an individual potter. At the same time, they are the result of different practical and symbolic factors.

Asurini potters choose clay deposits based on technical performance criteria such as plasticity and workability, ability to fire, and, while in use, thermal shock resistance. As observed among other pottery producing groups (Gosselain 1992: p. 565; Longacre 1991: p. 97), Asurini potters select clay mostly because of its performance in accordance with the technical requirements of the potter. For the Asurini, the distance of the deposits and their mineralogical composition are not considered major factors for this choice. This is not what scholars have observed in other groups (e.g., Arnold 1971, 1985). As previously noted, the deposits explored by the Asurini, although found close to the village, are differentiated in terms of clay characterization; differences they pointed out themselves. ${ }^{7}$ These differences, however, are not discussed in conceptual terms, since both clays are generally defined as ja'euma (clay) and are used indiscriminately in the production of all vessel types. It is important to emphasize that this selection of clay deposit is also intimately related to the fact that the Asurini potters do not use any kind of temper on the ceramic paste. According to them, it is inconceivable to add any substance to the clay because this would alter the vessels' texture in terms of its surface, which, as I have discussed, should be carefully smoothed. Thus, the clay they use contains an amount of sand that serves as a natural temper (Rice 1987: p. 408). Among other pottery groups, it has been observed that the use of temper can be applied both to modify the original clay properties, as well as to serve as a distinguishing element within the pottery communities, according to the local manufacture tradition (Braun 1983; Dietler and Herbich 1989: p. 152; Schiffer and Skibo 1987).

The Asurini produce vessels that have, at the same time, a certain functional efficiency and aesthetic as well as symbolic dimension. Thus, the vessels are constructed following a proportion in relation to form; and they usually have thin and very smooth walls. These choices, according to my sources, provide the vessel with greater efficiency in terms of cooking food (vessels used over a fire), as well as contribute to the vessel's

\footnotetext{
6 "Situational factors are defined as the behavioral, social, and environmental externalities that impinge on the activities of an artifact's behavioral chain and are embodied in each activity's specific components" (Schiffer and Skibo 1997: p. 34).

${ }^{7}$ Nowadays, the Asurini explore a clay deposit approximately $17 \mathrm{~km}$ from their village. It has the same characteristics of performance of the ones I investigated during my $\mathrm{PhD}$ research.
} 
aesthetic quality and serve as an indication of the potter's skill. Likewise, painted vessels become vehicles to transmit the world view of this population.

The specific use of a vessel leads to technological choices that result in a certain form, corresponding to the necessities of its performance. Vessels used to serve food are painted, have out-flaring rims, and are given an impermeable resin application only on the internal surface. Vessels used to transport liquids have a restricted mouth diameter to facilitate the acts of serving and transporting. Those designated for sale are medium and small sized, and, sometimes, they are made with thicker walls to avoid breakage. Pots destined to sell outside the village can be easily distinguished from daily-use pots, and potters even produce a set of unconventional forms meant only for sale. Finally, cooking pots are given an additional layer of impermeable resin on the external and internal surfaces; these pots have a spherical shape, out-flaring rims and are left without painting. All of these choices are made from the potter's knowledge about raw materials, the production process, the vessel's functions, aesthetic qualities, and symbolic meanings that these objects should present. This, in turn, is the result of a long process of learning and empirical practice.

The teaching-learning structure of knowledge on ceramic production is characterized by observation, by the young potters, of the work done by the more skillful potters. Beginning when the girls are very young, they are given practical instruction in the production of the vessels, which include how to work with all the raw materials and instruments related to this activity. Furthermore, they are encouraged to produce miniatures of the traditional ceramic vessels.

As has been observed in other ethnographic contexts, the more control the instructor has over the novice during the process of learning and creation of a material item, the more similar the objects they produce will look (Pryor and Carr 1995: p. 280; Roe 1995: p. 51). Thus, among the Asurini, where there is a high level of control in the ceramic learning process, one can in fact observe similarity not only in the objects but also in the procedures used to produce them. The teaching and learning process is so tightly controlled that the Asurini pots are unmistakably different from those of other cultural groups.

Nonetheless, it is possible to discern internal differences between the vessels produced by the potters, more particularly in the object's finishing details. Among the Asurini, the individual differences between the potters appear on the vessels' surface finish, especially the painting, where the tayngava structural pattern can be executed with different compositions on the vessel's body. Differences may also be seen, more subtly, in the structural patterning of the vessels, since the older women produce more accurate and well-finished ceramic vessels.

Therefore, one can say that, even if there is a technological tradition shared by the different group members, at the same time there are idiosyncratic behaviors that particularize some aspects of the productive process, and sometimes these can be identified on the material culture. These behaviors, however, are not contrary to the technological tradition, but instead reinforce the traditional formal aspects.

\section{Relationship Between Use and Quantitative Variability}

In the analysis of the relationship between use and quantitative variability, one must first consider the types of use for the artifacts in study. According to Shott (1996: pp. 
464-65), in terms of ceramic artifacts there can be only two general types of usepassive and active. Passive use of pottery does not involve excessive manipulation of the vessel or exposure to extreme physical and mechanical conditions. On the other hand, active usage implies that the vessel is exposed to continuous physical change and intense handling. Passive usage involves vessels used mostly for food and liquid storage, while active use often involves the transporting and processing of food, implying that the vessel can be put directly over the fire and/or be constantly handled. Thus, depending upon the type of usage, the artifact might suffer more or less damage and, consequently, will be produced in greater or lesser quantities. According to Mayor (1994: p. 179), ceramic artifacts that are constantly exposed to fire, such as those used for processing food, usually have a shorter life cycle and, as a result, they need to be replaced with more intensity.

This aspect of the ceramic artifacts' use life is also directly related to the production technology, since it has an impact on vessel durability. As pointed out by Sinopoli (1991: p. 84), "several ethnographic and ethnoarchaeological studies of pottery raw materials have shown that the constituents of cooking pots often differ from those of non-cooking pots. Many of the differences seem to be due to the desire to increase the ability of cooking pots to resist thermal stresses associated with repeated heating and cooling" and in this way avoid the frequent damaging and the necessity for replacement. This, however, is not the case observed among the Asurini potters, who use the same raw material to make cooking and non-cooking vessels. Yet, the japepa' $i$ and jape'e vessel types, constantly used over fire, break with more frequency than the non-cooking pots. The difference between cooking and noncooking pots is in the surface finish and the vessel's form. That is to say, the cooking vessels are not painted and thus they do not get jatobá resin application.

According to Arnold (1985: p. 153), firing atmosphere and temperature also influence the vessel frequency in the archaeological record. Vessels produced in oxidizing atmospheres and low temperatures have less strength and can be damaged more easily. As mentioned earlier, the Asurini fire their vessels in oxidizing atmospheres and low temperatures, and as a result they are susceptible to breakage and there is a need for replacement. Besides, the Asurini strive to produce thinwalled pots, especially the cooking pots. As indicated by Skibo (1999) and Skibo and Blinman (1999), cooking pots with thinner walls are weaker in terms of impact resistance but stronger when one considers thermal shock resistance. Asurini cooking vessels are resistant to thermal shock, but they have poor impact resistance. This last characteristic causes the potters to produce a large number of cooking vessels and increases the number of this vessel type in the village. Table I shows the large number of japepa' $i$ (cooking pots) as compared to the other vessel types.

Food processing technique is another element that should be considered when making inferences from ceramic data. Some forms of food processing require only a few vessels, while others need many more. At the Guatemalan site of San Mateo Ixtatan, a large number of vessels was found in each domestic unit (about 57 vessels), a fact thought to be related, among other things, to the processing of corn (Nelson 1991). Corn was the dominant item in the diet of the residents of this site and it required "most time and effort in preparation, and correspondingly involves the greatest amount and variety of pottery" (Nelson 1991: p. 168). Thus, during preparation 11 different vessel types were used besides those for transporting water. 
Table I Vessel Type Frequency in Asurini Village (Census 1998)

\begin{tabular}{lrlr}
\hline Vessel type & Amount & Vessel type & Amount \\
\hline Jape'e & 26 & Jape'I & 2 \\
Japepa'I & 163 & Jaeniwa & 24 \\
Já'e & 26 & Japu & 7 \\
Japui & 5 & Ywua & 33 \\
Yawi & 9 & Piriapara & 2 \\
Jarati & 2 & Yawa & 9 \\
Uira & 3 & Pupijanekanawa & 1 \\
Kume & 2 & Kavioi & 1 \\
Jukupiapara & 1 & Pequia & 1 \\
\hline
\end{tabular}

These vessels are counts from houses in the Asurini village

In the Asurini case, in contrast, food processing requires basically two ceramic types - the japepa' $i$ and the jape'e. Because these particular types are used more frequently, their frequency within the village increases. The daily use cooking pot (japepa ' $i$ ) is used most frequently, and it is also more abundant in the village. The practical importance of this vessel is mirrored, in this case, by symbolic importance. The japepa' $i$ plays a key role in the ture ritual, which occurs during the corn harvesting months, when a great demand is put on japepa' $i$ use and production.

The second aspect that should be considered when discussing the relationship between usage and quantitative variability is related to the vessels' intensity of use. Some researchers have shown that daily use pots that are handled more often usually suffer more damage, and, as a result, need to be replaced more frequently and appear in a greater number within the material record (Arnold 1985: p. 153; DeBoer and Lathrap 1979: p. 127). At the same time, others have noticed that there is not always a direct correlation between the intensity of use and the frequency with which a vessel would be found in the archaeological record (Sinopoli 1991: p. 86). This is the case, for example, for the larger vessels used every day to store food and liquids. Consequently, it is often the case that larger vessels have a longer use life - even when these are intensively used - and therefore they could be not properly represented in the archaeological record (DeBoer and Lathrap 1979: pp. 127128; Mayor 1994: pp. 189-194; Neupert and Longacre 1994; Shott 1996).

In terms of Asurini pottery, the relationship between vessel type usage and frequency within the artifact group varies according to the type of vessel considered. Thus, for the japepa' $i$ vessel type, as well as for the other vessel types traditionally used to serve, store and transport food, there is a direct relationship between the frequency of use of the vessels in each household. The relation is reversed, however, when one deals with the jape'e vessel type, which, although being intensively used on daily activities, is found in relatively low numbers in the household. The frequency of jape'e vessels is similar to that of types that have restricted usage, such as those used specifically in a ritual context (ja'e) or made for sale (jaeniwa, ja'e and ywua). As Table I shows, japepa' $i$ vessels are approximately 6 times more common than the other types found in the artifact group. Undoubtedly, this can be explained in part by their symbolic importance, as previously mentioned.

The low frequency of the jape'e type, despite its use frequency in the processing of manioc flour, may be a result of technological factors that make this vessel type less prone to breakage. That is, because it is produced with walls thicker than that of 
Table II Japepa'i Vessel Production per Domestic Unit (Census 1998)

\begin{tabular}{|c|c|c|c|}
\hline Domestic unit & Maximum diameter & Domestic unit & Maximum diameter \\
\hline \multirow[t]{2}{*}{ House 2} & 28 & House 10 & 42 \\
\hline & 34 & House 11 & 38 \\
\hline House 3 & 37 & & 40 \\
\hline \multirow[t]{5}{*}{ House 5} & 40 & & 27 \\
\hline & 40 & House 14 & 35.5 \\
\hline & 24 & & 34.5 \\
\hline & 32 & & 41 \\
\hline & $52 *$ & & 34 \\
\hline \multirow[t]{5}{*}{ House 6} & 37 & House 15 & 34 \\
\hline & 37 & & 31 \\
\hline & 40 & House 16 & 38 \\
\hline & 36 & & 30.5 \\
\hline & 29 & & 39 \\
\hline \multirow[t]{6}{*}{ House 7} & 33 & & 33 \\
\hline & 27 & & 32 \\
\hline & $48 *$ & & 20 \\
\hline & 39 & & 40 \\
\hline & 27 & & 36 \\
\hline & 37,5 & & 37 \\
\hline House 8 & 31 & & 35 \\
\hline \multirow[t]{6}{*}{ House 9} & $49 *$ & & 33.5 \\
\hline & 32 & & 41 \\
\hline & 28 & & 26 \\
\hline & 15 & & 37 \\
\hline & 18 & & \\
\hline & 13 & & \\
\hline
\end{tabular}

the other types, it presents more mechanical resistance to handling. As a rule, the smaller the vessel's walls curvature, the more it seems to be its resistant to fractures (Braun 1983: p. 118; Bronitsky 1986: pp. 254-259). In this sense, the jape'e has a form that guarantees a use life longer than that of the japepa' $i$ vessel type, whose recurrent breakage pattern on the rim and base exemplifies this supposition.

At the same time, the Asurini data in part confirm what was found in other pottery-making groups in relation to the larger vessels. The bigger vessels, according to my informants, also possess a use life longer than that of the smaller vessels. ${ }^{8}$ However, contrary to what was observed in other ethnographic contexts, the larger Asurini vessels are also used less frequently. This is the case, for example, of the big japepa' $i$ vessel type (approximately $50 \mathrm{~cm}$ maximum diameter), which is used more frequently in the processing of stews in ritual context and not in daily food production. These larger japepa'i vessels are produced less frequently than the smaller japepa'i. I could observe this different productive demand in March 1998, during the corn harvest. As seen in Table II, few japepa' $i$ vessels with diameters greater than $45 \mathrm{~cm}$ were produced. These larger vessels were produced by married women, older than 45 years. The group thought them to be skillful potters; they did not have small children to care for, allowing them more time to work with pottery.

\footnotetext{
${ }^{8}$ The knowledge obtained through interviews with Asurini informants must be understood as being the general pattern observed from the vessels' use life, since I have not conducted a systematic research on the use of the ceramic vessels.
} 
The idea here is to demonstrate that within the Asurini context the larger vessels appear less frequently because their production requires more skill and time.

The last aspect to be considered when analyzing the relationship between use and quantitative variability is the context and method of use. Some researchers observe that vessels used close to the floor are subject to more accidents involving children, adults and animals. In addition, vessels that are frequently moved from one place to the other are usually damaged more often than those that stay stationary and/or are placed in higher or more protected places. In this sense, the larger vessels are seen as less subject to breakage and replacement, which results in their lower frequency in the household. This happens because they are seldom relocated and are in places where there is not intense traffic of people and animals (Arnold 1985: p. 153; DeBoer and Lathrap 1979: pp. 127-128). DeBoer (1983: p. 28) also suggests that the low frequency of larger-sized vessels observed in different ceramic contexts can be explained by their manufacturing cost, which is much higher and requires greater care during use.

Among the Asurini, the large-sized japepa'i and jape'e vessel types are usually manipulated with care. So, when moving a japepa' $i$ filled with food, special care is taken so that it is carried by positioning the arms around its whole body. In certain situations, two women will carry the full vessel. When it is empty, it is carried with its mouth faced outward by holding it against one's body, with a hand between the end of the neck and the beginning of the body. The jape'e is carried by holding it close to one's body, with the hands on the rim and the internal surface facing outwards. These vessels are hardly ever left over the hearths after use; they are cleaned and stored inside the houses, and, preferably, leant against the walls or places with little foot traffic.

Taking into account DeBoer's (1983) statement on manufacturing cost, as well as the Asurini vessels' type and size data (Tables I and II), one can say that the manufacturing cost of these vessels is the likely explanation for the way they are used and their low household frequency. As mentioned earlier, according to my sources, the manufacturing of a big japepa'i or jape'e requires accuracy and practice, and it is attempted only by those who are considered the most skillful for this type of production. At the same time, they also point out that the bigger vessels take longer to produce in terms of vessel manufacturing and drying and smoothing time; it can take up to 10 days to produce it. But the most difficult aspect of making these larger vessels, they say, is to fire them without breaking.

Another vessel that requires a careful storage and restricted use is the ja'e type employed in rituals. This type of vessel is kept on racks inside the houses and it is manipulated during ritual performance. According to the Asurini, its use life is very long, but they could not give an estimate in terms of years. All of the vessels that I saw in use, however, had a great deal of use alteration, mainly erosion in the painting. One must also take into account the Asurini cosmological system to understand the use of this vessel type and vessel frequency. As indicated by Müller (1990: p. 178), the vessels employed during rituals to serve the porridge and to transmit the ynga (vital energy) and the moynga (medicine) to their participants have an appearance of negligence and deterioration, what can be interpreted in this way: "it marks them as objects belonging to the spirits, distinguishing them from the humans." The Asurini believe the supernatural beings live in places where there is no 
clay to produce ceramic vessels. As a result, they cannot produce new vessels and must use the same old vessels indefinitely.

As for daily use vessels, the Asurini follow patterns observed in other ethnographic cases mentioned above. The japepa' $i$ vessels are used in such a way that it is easier for them to be damaged and broken. In other words, they are often used on the ground or floor within the domestic space and are exposed both to children's games and adult carelessness.

This study has shown that it is very important for the archaeologists to explore the cultural processes that could have been responsible for the quantitative variability of pottery types. Use frequency and the manner and context of use are interdependent variables, and this should also be taken into consideration when one makes inferences about past behavior based on the relative number of diverse ceramic types.

\section{Relationship Between Reuse and Quantitative Variability}

Reuse is a process where material items, after they have exhausted their primary function, are retained in their context of use but not used for their originally intended purpose. According to Schiffer (1987: p. 28), "the manner in which societies retain artifacts in systemic context through reuse (and discharge materials to the environment through depositional processes) determines many characteristics of the archaeological record", like, for instance, their frequency in different activities and discard areas. Schiffer et al. (1995: p. 107) observe several different varieties of reuse, which include lateral circulation, recycling, secondary use and conservation.

Lateral cycling involves a change in the use of the object without changing form and function. Among the Asurini, I observed this process with the large japepa' $i$ vessels, as well as with the jape'e. Both circulate among the women of the same domestic group, but who live in different domestic units. Between the two vessel types, the jape' $e$ is more frequently borrowed for daily activities, while the japepa ' $i$ is loaned to other households on ritual occasions. This lateral circulation of vessels is always temporary, and loaned vessels are always returned to their owner. This kind of cycling of vessels can be seen as an index for the importance of social relationships among the women within each domestic group.

From the archeological point of view, as indicated by Schiffer (1987: p. 29), this type of reuse can be difficult to identify, since it does not require formal modification of the material item. The recycling process, on the other hand, modifies the object in terms of its original characteristics, and it produces traces on these artifacts that, in archeological terms, make possible its identification. This is the case, for instance, in the processes of reuse of sherds as temper in pottery production (La Salvia and Brochado 1989: p. 16), or as construction material to repair walls of structures (Sullivan 1989). Among the Asurini, ceramic recycling is seen more often during the application of the jatobá resin to the vessel's external face. Women will take large sherds, shape them as needed, and subsequently use them as a shield to the excessive heat while the resin is applied.

Secondary reuse was also observed among the Asurini. This is the process where an artifact without any visible change in form is used for a purpose for which it was not designated. Secondary reuse can include artifacts that cannot satisfactorily 
accomplish their primary function any longer, although they may appear visibly undamaged (Schiffer 1987).

Among the Asurini, pottery is always employed for this kind of secondary use, independent of the degree of its damage. For example, both the japepa' $i$ and jape'e type vessels used in the processing of daily food, and also those of the other types that are produced mainly for sale, are reused in the context of the village. The broken japepa' $i$ and jape'e vessel types are often reused as supports for new vessels over cooking fires or as kiln furniture when other pots are fired; those of the japepa' $i$ type are also reused to cook babassu oil or to put the jenipapo pigment used on body painting. The process of vessels' reuse leaves marks in these vessels: for instance, the presence of jenipapo paint in the interior of sherds employed as containers for the body paint, residues of babassu oil processing, and the almost complete deterioration of the layer of impermeable resin originally applied; or soot remains in the external and internal faces of the vessels that were used as support in the stoves or as the base for the structures of ceramic firing.

As it has been pointed by some authors, in the study of the ceramic vessels found in the archeological record, these reuse processes can sometimes be identified through analyses of residues (fats, oils, resins, salts and carbohydrates) if they were deposited during reuse. In addition, the reuse may have left marks or other traces on the surface that can be linked to a particular reuse activity (Rice 1987: pp. 233-35; Skibo 1992: pp. 113-141, 148-157). In the case of the reused vessels among the Asurini, use-alteration traces on the base and exterior surfaces, like soot, would provide revealing signs of reuse, as would the abrasive interior marks that come from boiling of babassu oil and the peeling of the resin.

These use-alteration traces should not be confused with traces created during the vessel's primary use. In the case of the japepa' $i$ vessels, abrasive marks on the internal face are created and some resin is removed when the contents are stirred with a wood or metal spoon. Cleaning the vessels' interior with a spoon or wood piece can also leave marks of this type in the surfaces and accelerate the process of damage to the impermeable resin. Soot is also deposited on the vessels' base when they are placed over fire. This also happens with the jape'e vessels type.

Another important type of secondary use among the Asurini is symbolic. The japepa' $i$ vessels are often deposited in the graves inside the tavyva (communal and ceremonial house). According to Schiffer (1987: p. 31), the identification of this type of reuse in the archeological record can be made only from a relational perspective; in other words, by the association of elements of the archeological context.

Schiffer (1987: pp. 40-46) states that settlements with longer occupation spans will have larger quantities of reused artifacts, and may have structures to store these items. In the Asurini case, the reuse of the ceramic vessels does require several storage structures. In addition, some of these stored objects are being conserved; that is, a form of secondary use resultes in the preservation of the artifacts that became vehicles to transmit messages of social and symbolic order. As I have already mentioned, the Asurini see the japepa' $i$ vessel type as the symbol of food, and it is an artifact within the feminine domain, since it is produced and used by women for the processing of food. Furthermore, some Asurini vessel types are painted with motifs that refer to the supernatural beings appearing in their mythic accounts, 


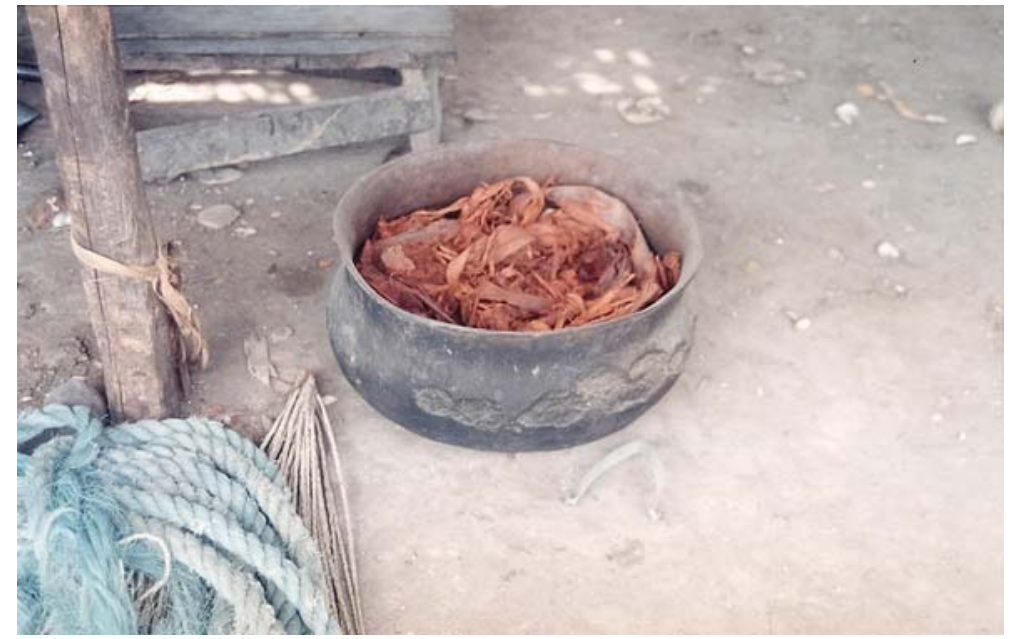

Fig. 19 Japepa'i vessel being reused to storage tree fibers.

similar to Roe's (1995) observations among many South American populations. Therefore, the preservation of ceramic vessels is, at the same time, a way to reiterate the women's social and economic importance in this society and give material form to the myths and cosmological principles of this cultural group. Reuse processes are not solely utilitarian; different factors can lead to the practices of retention, reutilization and preservation of objects in the material record and, consequently, determine their frequency in this record (Fig. 19).

\section{Relationship Between Storage and Quantitative Variability}

In his study among the pottery community of San Mateo Ixtatan, Guatemala, Nelson (1991) found that the frequency of ceramic vessels in a village was related not only to the technology of food production, but also to the storage procedures carried out by this population. According to him, there are two types of storage: stockpiling and dead storage. He defines stockpiling as "the accumulation of new vessels for eventual use," while dead storage is "the retention of old vessels after their useful life is basically exhausted" (p. 171). As Nelson demonstrated, houses in this community had many vessels that were not used on a daily basis, yet they were distributed inside the houses, near the walls, on crossbars that sustained the roof, and outdoors. Stockpiling was easy to understand, since it is important to have a ready supply of short-lived cooking vessels. Moreover, he explains that in this community not all domestic groups have their own potters, making it difficult to replace a broken pot. "To get a new pot, one usually must have cash, a market day, and a potter present with the right product. The probability of these conditions occurring simultaneously is somewhat low, since market days are infrequent, cash is scarce and pottery is made seasonally even by specialists" (p. 171). On the other hand, when he refers to dead storage, he states that "it is not as easy to explain," and in the end these vessels were being used very often as "containers for other objects that have no apparent use" (p. 171). 
In the Asurini village, both types of vessel storage could be observed. Even though all Asurini domestic groups have their own potters, and thus the replacement of a broken vessel does not present the same problems it does in San Mateo Ixtatan, the practice of stockpiling is observed in the village. As has been previously mentioned, the interior of the houses is replete with vessels that simply lean on the internal walls or are stored face down on crossbars and racks. In most cases, these are either new vessels of diverse types kept for sale, or the infrequently used large japepa' $i$ and jape'e vessels that are stored there and taken down when needed. On the other hand, in the spaces between the houses within the village, a great number of used and damaged vessels of different sizes and types (besides the painted ones) are stored, this being a case of dead storage. They are placed on the ground, leant against the external walls of the houses or put inside the structures that serve as kitchens. The storage of vessels (both new and used) is also done in enclosed structures that serve solely to hold ceramic vessels.

These storage procedures among the Asurini result from several factors. First, many of those vessels, especially the cooking vessels, have a relatively short use life, owing both to their technological choice in manufacture and their use. People must replace the vessels very often and have a supply of appropriate pots in storage. Second, they usually store used or damaged pots for diverse later reuses or discardthis sort of storage could also be understood as a process of "provisional discard" (Deal 1985). Finally, the ceramic vessels have symbolic importance to the Asurini. In other words, they are vehicles that transmit messages of their world view, as I have already explained. Therefore, they do not want to throw away the pots.

Although the storage procedures are carried out by all the women independent of the domestic group they belong to, the resultant frequency in each one of the domestic units is not constant, as is demonstrated in Table III. The houses with the most vessels are: house 3 (56 vessels), house 4 (32 vessels), house 11 (23 vessels), house 9 (12 vessels), house 14 (19 vessels) and house 16 (27 vessels). This can be partially explained by the women's willingness to produce new vessels or, on the other hand, for their concern in storing them.

In the village, the houses that possess the greater number of vessels were houses 3, 4 and 16. Houses 3 and 4 possessed many vessels because, as I was told, they had been producing more than what they needed for the last 5 years at least. This is particularly true in house 3 , where a skilled potter lived who dedicated a good part of her time to vessel production. A higher number of active potters in the household could also influence the number of stored pots. In houses 11 and 16, for example, there were respectively three and four potters. The number of potters, however, is not the only factor, since there are houses (9 and 14) that have just one or two potters and yet have many vessels in their household.

A relationship between the number of individuals in the household and the number of vessels may seem logical, but a significant number of ethnographic studies have demonstrated that this is not the case (DeBoer and Lathrap 1979: p. 124; Nelson 1991: pp. 169-171). This is also true among the Asurini. In addition, the number of vessels used daily does not increase in accordance with household size. In other words, the number of vessels used daily by household is not related to the number of people who use them, as seen in Table IV. 


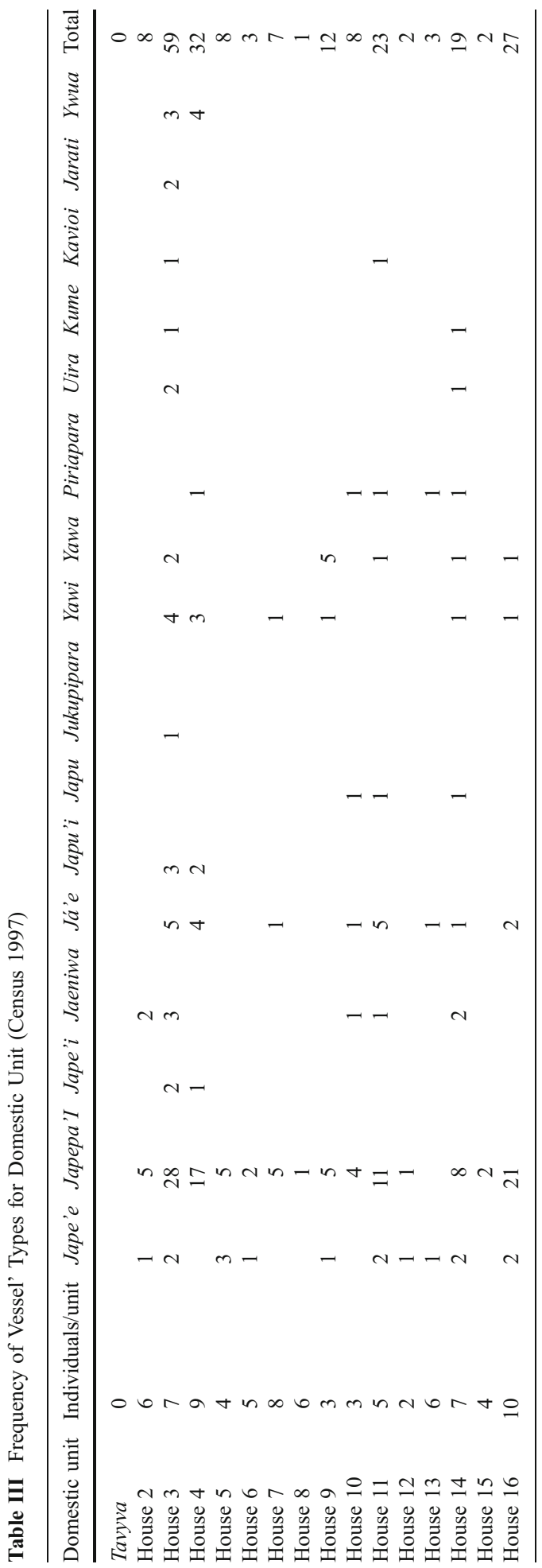


Table IV Frequency of Vessels Types in use for Each Domestic Unit (1997)

\begin{tabular}{|c|c|c|c|c|c|c|c|}
\hline Domestic unit & Individuals/unit & Jape'e & Japepa'i & Domestic unit & Individuals/unit & Jape'e & Japepa'I \\
\hline House 1 & 2 & & 2 & House 9 & 3 & 1 & 5 \\
\hline House 2) & 6 & 1 & 2 & House 10 & 3 & & 2 \\
\hline House 3 & 7 & 2 & 5 & House 11 & 5 & 2 & 1 \\
\hline House 4 & 9 & & 3 & House 12 & 2 & 1 & 1 \\
\hline House 5 & 4 & 1 & 1 & House 13 & 6 & 1 & \\
\hline House 6 & 5 & 1 & 2 & House 14 & 7 & 2 & 5 \\
\hline House 7 & 8 & 1 & 1 & House 15 & 4 & & 1 \\
\hline House 8 & 6 & & 1 & House 16 & 10 & 2 & 3 \\
\hline
\end{tabular}

The average number of vessels for each meal is 2 to 3 japepa ' $i$ and 1 to 2 jape'e, regardless of the number of individuals in the domestic unit. The exceptions were houses 3, 9 and 14, where they were using 5 japepa' $i$ vessels. According to my sources, this was not related to the amount of food produced, but simply their availability of use. A woman said that the use of several vessels means that less vessel cleaning is done.

The Asurini behavior regarding reuse and storage highlights the complexity of the factors that determine the frequency of certain objects in the material record. Archaeological inferences based on frequency should take into consideration the practical and symbolic factors that can have an impact on vessels' use, reuse, and storage.

\section{Relationship Between Activity Areas and Spatial and Relational Variability}

The spatial locations of artifacts in the archeological record can reveal the behavioral dynamics of spatial use in the context of a variety of social components (gender groups, domestic groups, groups of age and tasks groups) both at the local and regional level (Binford 1983a, b, c; Brooks and Yellen 1987; Kent 1984: pp. 136184; Schiffer 1987: pp. 17-18).

Relational variation, on the other hand, refers to the associations among the artifacts in the material record. Associations can be divided up into two types, singular and recurrent. A singular association refers to the discovery of two or more items in close proximity. Recurrent associations describe the situations one encounters when singular associations turn out to be so not singular after all, because the same items are found together again and again, often in different recovery units (Schiffer 1987: p. 20). It is clear that the spatial and relational dimensions of artifact variability are interrelated variables. Understanding formation processes is critical in interpreting spatial and relational variability among artifacts (Schiffer 1995, 1983; Binford 1980, 1991. Three concepts are commonly employed to explain depositional processes: primary refuse, secondary refuse, and de facto refuse (Schiffer 1995). In ethnoarchaeological studies of the use of space, the archaeologists' main concern is to understand the relation between activity, activity area and material discard (e.g., Binford 1980, 1983d, e, 1989, 1991; Gould 1978, 1980; Kent 1984, 1987; Yellen 1977).

The Asurini village has two types of activity areas: those of public and/or communal activities (ceremonial square and tavyva) and those of private activities 
(domestic units, storage structures, kitchen facilities and patios). Among the Asurini, there is a spatial regulation whose emphasis is in maintaining zones related to the different domestic groups. In this way, the domestic units that shelter the individuals belonging to the same domestic group are spatially organized in a way to bind together the individuals that maintain a relationship of daily cooperation.

The public area is reserved for the performance of ritual activities, as well as communal activities such as political, administrative, social, and economic discussions. This area has few material remains and it is frequently cleaned by the members of the village. Individuals from each domestic group are responsible for cleaning the communal space in front of their house.

Ceramic manufacturing activities occur, for the most part, within the domestic space (kitchen facilities, home units, attached structures and the patios between the houses). Two activities, the preparation of pottery making raw material and the firing, are conducted outside the domestic space. Some of these vessel production materials include clay (processed and unprocessed), stones used as pigments, remains of tree bark (titiva), instruments (painting brushes, babassu raquis and wood forks with pitch tracks, bottle gourd spatula and coconut with clay tracks), supports for the coils' production, and vessels with water, as well as stones and sherd wasters.

During the Asurini ceramic manufacture, the potters generally create an activity area delimited by artifacts that surround them. Most of the time, this specific activity area is maintained only while the artisan is still working, because it takes place in multifunctional space. For example, pottery making areas can also be used for preparation and consumption of food, painting and body decoration, storage of food and other items, and the making and recycling of crafts. At the same time, these areas are for social and family feasting, and also a place to participate in shamanistic practices and ritual performances. The dynamic nature of these activity areas means that potters do not have any permanent space, and many times they have to collect their tools and interrupt their manufacturing activities because other activities need the space, or because they are worried that increased traffic near their work, especially children, will damage their pots. In other ethnographic contexts, under similar situations, special structures were built for craft activities (Binford 1991: pp. 223-224). No such structures were used by the Asurini to protect their craft making activities.

As a result of the multifunctionality of special areas, the remains of the ceramic production processes, as well as the unfinished objects, could have become associated with items related to other activities. The most common associations happen between: (1) unfinished vessels and utensils for transport, preparation of food and domestic and personal comfort (e.g., graters, sieves, baskets, ceramic vessels in use, fans, industrialized products, spoons, stoves, rack and mats) deposited in kitchen areas, inside domestic units and attached structures; and (2) vessels or babassu leaves with clay and transport utensils, storage of several materials and work implements (e.g., industrialized tools, damaged ceramic vessels, baskets, anvils and lithic hammers, and industrialized containers) deposited in kitchen areas, the external walls of the houses and attached structures.

Pottery is also used in these multifunctional activity areas, and thus it can be associated with the same variety of items that were found in the pottery making areas. A vessel's use is related to its morphology; in other words, each type is related to a specific activity or use, such as the preparation, consumption, transport and 
storage of foods and several materials, sale, and ritual performance. These different uses, by the way, result in the different spatial location of the vessels in each different activity area. In this way, in the area of public domain, as is the case of the central space of the tavyva, the tauva rukaia vessel is in association with the graves, to which a big japepa' $i$ type vessel, previously used in the domestic space, is also associated. In this area, we found all of the vessel types whose location, as previously mentioned, corresponds to the use that these vessels are destined for in the daily activities. Thus, the japepa' $i$ and jape'e vessel types in use are placed in the areas of domestic activities destined for the preparation, boiling and consumption of food, and, eventually, they can be kept inside the domestic units to be used later. The other types, destined mostly for sale, are deposited always inside the domestic units or in attached structures, where one can also find the damaged vessels destined to be reused.

It is important to observe that potters store new vessels in areas protected from the weather and foot traffic, whereas the worn out pots are stored outdoors or in less protected environments. In addition, new and worn out stored vessels are usually restricted to the activity areas of the domestic space. Some of these areas within the domestic space can be seen as "provisional discard areas" (Deal 1985) and, just as it has been observed in other contexts, the rubbish deposited there "is susceptible to various attritional processes, including (1) further accidental breakage, (2) weathering, (3) the caprices of children's play behavior, (4) the effects of animal activities, and (5) retrieval of selected pieces which may be subjected to a recycling use that has been found (e.g., uses of pot bodies as plant protectors, use of large sherds as ash scoops, etc.)" (Hayden and Cannon 1983: pp. 131-132). Usually, the larger sherds that are not recycled for use are picked up and moved to a specific discard location, while the smaller pieces are deposited as primary refuse. In Asurini domestic areas, it is very common to observe a scatter of sherds. When individuals circulate in the domestic space the sherds are trampled, broken into smaller pieces and buried in the surface.

Besides the characterization of areas of activities (unifunctional and multifunctional) and the type of refuse present in each one (primary, secondary and de facto), it is important to consider the effect of seasonality on activities (Kent 1984: p. 65). Among the Asurini, some of the domestic activity areas are less intensely used during the rainy season. For example, between November and April, pottery production, and preparing and consumption of food takes place primarily in areas protected from the rain. Thus, artifact use, breakage and deposition are different during the dry and rainy seasons.

Finally, it is important to point out that the domestic activity areas are also routinely cleaned. In agreement with Binford (1991: p. 235), it is the more intensively used areas that receive more maintenance. Among the Asurini, the cleaning of areas used to process and consume food occurs frequently, but not necessarily on a daily basis, as was observed among the Shipibo-Conibo (DeBoer and Lathrap 1979: p. 12).

\section{Relationship Between Discard and the Spatial and Relational Variability}

According to Schiffer (1987: pp. 47-49), when an artifact loses its capacity to accomplish the function for which it was originally produced and, at the same time, 
it is not destined for reuse, it will, usually, be discarded. The reasons for the discard of artifacts are varied, including obsolescence, undesirable deterioration, and breakage or wearing away due to use.

Among the Asurini, the major reason for final discard of ceramic vessels is breakage during use and storage. A less frequent cause, however, happens when a potter dies and her vessels are no longer wanted in the village, being taken to the discard areas surrounding the village. More often, the final discard of ceramics occurs during the process of cleaning the activity areas. Small pieces of ceramic vessels can be observed around the cooking structures, a result of occasional damage of the vessels during use. From time to time, these areas are swept and the ceramic remains, together with other remains (food, basketry, etc.), are deposited in the discard areas.

These discard areas of "secondary refuse" (Schiffer 1995: p. 31) appear in three distinct forms: (1) dispersed in the village's outskirts, usually below areas of domestic activity; (2) concentrated in the form of middens, surrounding the domestic areas; and (3) in the form of pits, in external areas between the domestic structures. In the first case, the discard area is extensive, shallow in depth, hidden under the vegetation and, sometimes, difficult to identify. The distribution of trash in the Asurini's area of discard is very similar to that found by Hayden and Cannon (1983: pp. 129) in the "toft area" in Aguacatenango. The middens, however, form garbage heaps that may occupy an area up to $40 \mathrm{~m}^{2}$ and reach $2 \mathrm{~m}$ in height, which is the case on the north side of the village, close to house 1 . This location has been used as an area of refuse disposal by domestic groups that inhabit that section of the village (houses 1, 2, 3, 4, and 5) for the past 10 years at least. Among the Asurini, the middens' use and localization are frequently related to the distribution of domestic groups within the village, an aspect that has already been observed in other contexts (Beck 2006; Beck and Hill 2004). Regarding the pits, it can be perceived that they are not regularly used in the village and, frequently, they are used by the domestic

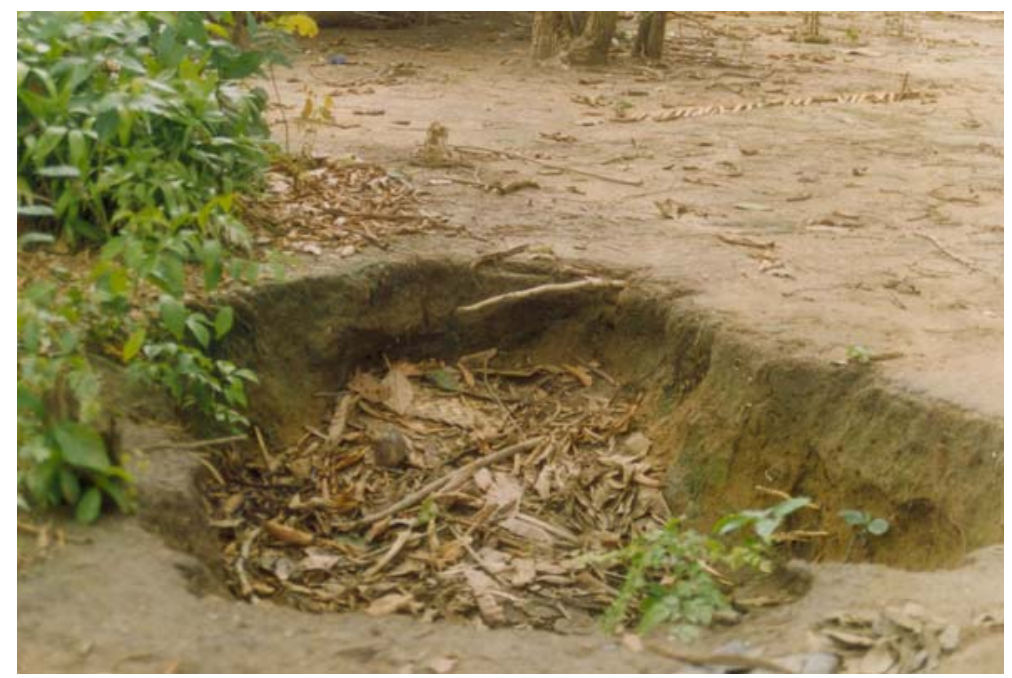

Fig. 20 Garbage pit in the Asurini village. 
groups, as a rule, to deposit inorganic vestiges that do not deteriorate easily (e.g., cans, glass, plastic). According to the Asurini, they learnt to use pits as a place to put garbage from FUNAI employees who used them to keep the Asurini from being exposed to dangerous materials (e.g., cans, medicine bottles, syringes, medical garbage, etc.) (Fig. 20).

As I have already mentioned, the ceramic vestiges that appear throughout all these discarding areas result from the vessels' breakage during use or storage. As stated by Beck (2006: pp. 42), there are two distinct models of ceramic discard: "(1) provisional discard of vessels and fragments in house lots, with final discard after some period of time; and (2) final discard of vessels at a time near its breakage." In the first case, the resultant ceramic sherds are small, since the vessels tend to be susceptible to various attritional processes. On the other hand, if the vessels are discarded soon after the episode of their breakage, one expects that the fragments found in the garbage deposits will be larger.

Among the Asurini, two types of discard behavior can be observed; the predominant one is the provisional discard, with the final discarding of vessels and sherds taking place a certain time after the episode of the breakage. In this sense, even though I have not conducted a systematic collection of ceramics in the discard areas, I could observe that they present a great amount of small-sized ceramic sherds.

To conclude, it is important to emphasize that, aside from the discard behavior, other factors must be taken into consideration to explain this type of ceramic deposition pattern in discard areas I researched; that is, the fact that they are subjected to constant processes of disturbance (e.g., children collecting, digging and breaking the materials; domestic animals searching for food; adults setting fire to the vestiges) (Silva 2003).

\section{Conclusion}

Each archeological deposit is a contemporary phenomenon made up of material remains that were formed, transformed and deposited through different natural and cultural processes. Consequently, the interpretation of the archeological record can be reached only if one starts from the understanding of these natural and cultural processes that influence and affect its formation.

It can be said that one of the main objectives of archeological research is to make an attempt at comprehending "the systemic context of things recovered from the archeological record" (Schiffer 1987: p. 4); in other words, the behavioral dynamics carried out by the past societies that made, used and deposited the material remains found by the archeologist.

Archeological contexts, however, do not speak for themselves, and the understanding of formation processes can be reached only if the archeologist develops theoretical-methodological tools to aid in his interpretation. Ethnoarchaeology is seen as one of these tools, since it explores the relations between human behavior and material remains. In this sense, contemporary indigenous populations like the Asurini can be an important resource for the archaeologist. In this and other Amazonian populations it is still possible to investigate the dynamics of the production, use, storage and discard of material items. 
In this paper on the subject of the Asurini ceramic vessels, I have made an effort to demonstrate that artifact variability results from technological choices the potters have made during the processes of production, use and discard of the ceramic vessels, and that these choices are themselves influenced by different elements of a practical and symbolic nature.

Regarding the formal variability, I found that it is related to the vessels' performance characteristics, presenting a direct connection between the technological choices, the form and the function of the vessel. As for the quantitative variability of the artifacts, I observed that the frequency of a particular ceramic vessel type results from aspects such as type, frequency, method and the context of use. Finally, while analyzing the artifacts' spatial and relational variability it also became evident that their location is determined by the activities they were submitted to during their use life.

The arguments developed in this article with regard to the technological systems and their relation to the artifact variability have made clear that ethnoarchaeological research is an essential tool for the understanding of the formation processes of the archaeological record. Furthermore, I emphasized the fact that the past cannot be explained by a single interpretative reference, since the cultural phenomena are extremely complex, presenting different contextual meanings. Hence, concerning the technological systems in particular, I have demonstrated that those should not be seen in the archaeological context solely as results from processes of the populations' adaptability in the past, but as a result of their social and symbolic dimension as well.

Acknowledgments In preparing this research, I have benefited from the knowledge of Lux Vidal, Regina Müller, and the generous Asurini people. I would like to thank the comments and corrections of JAMT reviewers, Jim Skibo, Catherine Cameron, and Francisco Noelli by the final inputs and suggestions. This work was possible due to scholarship provided by the Conselho Nacional de Desenvolvimento Científico e Tecnológico - CNPq (1995-1999), and founds by the Fundação de Amparo à Pesquisa de São Paulo - FAPESP (1996-2006).

Open Access This article is distributed under the terms of the Creative Commons Attribution Noncommercial License which permits any noncommercial use, distribution, and reproduction in any medium, provided the original author(s) and source are credited.

\section{References}

Arnaud, E. (1983). Mudanças entre os Grupos Indígenas Tupi da Região do Tocantins-Xingu (Bacia Amazônica). Boletim do Museu Paraense Emílio Goeldi, N.S. Antropologia 84.

Arnold, D. E. (1971). Ethnomineralogy of Ticul, Yucatan Potters: Ethics and Emics. American Antiquity, 36(1), 20-40.

Arnold, D. (1985). Ceramic theory and cultural process. Cambridge: Cambridge University Press.

Balée, W. (1988). Indigenous adaptation to Amazonian palm forest. Principles, 32(2), 47-54.

Balée, W. (1989a). Nomenclatural patterns in Ka'apor ethnobotany. Journal of Ethnobiology, 9(1), 1-24.

Balée, W. (1989b). The culture of Amazonian Forest. Advances in Economic Botany, 7, 1-21.

Balée, W. (1994a). Footprints of the Forest (Ka'apor Ethnobotany-the Historical Ecology of Plant Utilization by an Amazonian Individuals). New York: Columbia University Press.

Balée, W. (1994b). Language, culture, and environment. Tupí-Guaraní Plant Names Over Time. In A. Roosevelt (Ed.), Amazonian Indians. From prehistory to the present (anthropological perspectives). Tucson: The University of Arizona Press. 
Beck, M. E. (2006). Midden ceramic assemblage formation: A case study from Kalinga, Philippines. American Antiquity, 71(1), 27-51.

Beck, M. E., \& Hill, M. E. J. (2004). Rubbish, relatives, and residence: The family use of middens. Journal of Archaeological Method and Theory, 11(3), 297-333.

Binford, L. R. (1980). Willow smoke and dogs' tails: Hunter-gatherer settlement systems and archaeological site Formation. American Antiquity, 45, 4-25.

Binford, L. R. (1983a). Forty-seven trips: A case study in the character of some formation processes. In L. R. Binford (Ed.), Working at archaeology (pp. 243-268). New York: Academic Press.

Binford, L. R. (1983b). Organization and formation processes: Looking at curated technologies. In L. R. Binford (Ed.), Working at archaeology (pp. 269-286). New York: Academic Press.

Binford, L. R. (1983c). Evidence for differences between residential and special-purposes sites. In L. R. Binford (Ed.), Working at archaeology (pp. 325-336). New York: Academic Press.

Binford, L. R. (1983d). Dimensional analysis of behavior and site structure: Learning from an Eskimo hunting stand. In L. R. Binford (Ed.), Working at archaeology (pp. 287-326). New York: Academic Press.

Binford, L. R. (1983e). The archaeology of place. In L. R. Binford (Ed.), Working at archaeology (pp. 357-378). New York: Academic Press.

Binford, L. R. (1989). An Alyawara day: Flour, spinifex gum and shifting perspectives. In L. R. Binford (Ed.), Debating archaeology. New York: Academic Press.

Binford, L. R. (1991). Em Busca do Passado. s.1.: Europa-América.

Braun, D. P. (1983). Pots as tools. In J. A. Moore, \& A. S. Keene (Eds.), Archaeological hammers and theories (pp. 108-134). New York: Academic Press.

Bronitsky, G. (1986). The use of materials science techniques in the study of pottery construction and use. Advances in Archaeological Method and Theory, 9, 209-276.

Brooks, A. S., \& Yellen, J. E. (1987). The preservation of activity areas in the archaeological record: Ethnoarchaeological and archaeological work in Northwest Ngamiland, Botswana. In S. Kent (Ed.), Method and theory for activity area research (An ethnoarchaeological approach) (pp. 63-106). New York: Columbia University Press.

Bunzel, R. (1972). The pueblo potter. A study of creative imagination in primitive art. New York: Columbia University Press.

Coudreau, H. (1977). Viagem ao Xingu. São Paulo, Itatiaia/EDUSP. 1977.

Deal, M. (1985). Household pottery disposal in the Maya Highlands: An ethnoarchaeological interpretation. Journal of Anthropological Archaeology, 34, 20-38.

DeBoer, W. R. (1983). The archaeological record as preserved death assemblage. In J.A. Moore, \& S. Keene (Eds.), Archaeological hammers and theories (pp. 22-37). New York: Academic Press.

DeBoer, W. R., \& Lathrap, D. (1979). The making and breacking of Shipibo-Conibo ceramics. In C. Kramer (Ed.), Ethnoarchaeology. Implications of ethnography for archaeology (pp. 102-138). New York: Columbia University Press.

Dietler, M., \& Herbich, I. (1989). Tich Matek: The technology of Luo pottery production and the definition of ceramic style. World Archaeology, 21(1), 148-154.

Douglas, M. (1976). Pureza e Perigo. Perspectiva, São Paulo.

Gosselain, O. P. (1992). Technology and style: Potters and pottery among Bafia of Cameron. Man, 27(3), 559-585.

Gould, R. A. (1978). The anthropology of human residues. American Anthropologist, 86, 815-835.

Gould, R. A. (1980). Living archaeology. Cambridge: Cambridge University Press.

Hayden, B., \& Cannon, A. (1983) Where the garbage goes: Refuse disposal in the Maya Highlands. Journal of Anthropological Archaeology, 2(2), 117-163.

Kent, S. (1984). Analyzing activity areas: An ethnoarchaeological study of the use of space. New Mexico: University of New Mexico Press.

Kent, S. (1987). Understanding the use of space: An ethnoarchaeological approach. In S. Kent (Ed.), Method and theory for activity area research (An Ethnoarchaeological Approach) pp. 1-60. Columbia: New York University Press.

La Salvia, F., \& Brochado, J. P. (1989). Cerâmica Guarani. Posenato Arte e Cultura, Porto Alegre.

Lemonnier, P. (1993). Introduction. In P. Lemonnier (Ed.), Technological choices. Transformation in material cultures since the neolithic (pp. 1-35). London: Routledge.

Lévi-Strauss, C. (1986). La Alfarera Celosa. PAIDOS STUDIO, Barcelona.

Longacre, W. (1991). Sources of ceramic variability among the Kalinga of Northern Luzon. In W. A. Longacre (Ed.), Ceramic ethnoarchaeology (pp. 95-111). Arizona: University of Arizona Press. 
Mahias, M. C. (1993). Pottery techniques in India. Technical Variants and Social Choice. In P. Lemonnier (Ed.), Technological choices. Transformation in material cultures since the neolithic (pp. 157-180). London: Routledge.

Mayor, A. (1994). Durées de vie des Céramiques Africaines: Facteurs Responsables et Implications Archéologiques. XIV Rencontres Internationales d'Archéologie et d'Histoire d'Antibes (pp. 179-198). Juan-les-Pins, Éditions APDCA.

Müller, R. (1984/85). Asuriní do Xingu. Revista de Antropologia, 27/28:91-114. São Paulo.

Müller, R. (1987). De Como Cinqüenta e Duas Pessoas Reproduzem uma Sociedade Indígena. Os Asuriní do Xingu. Tese de Doutorado em Antropologia Social, Departamento de Antropologia. Universidade de São Paulo.

Müller, R. (1990). Os Asuriní do Xingu (História e Arte). Editora da UNICAMP, Campinas.

Müller, R. (1992). Tayngava, a noção de representação na arte gráfica. In: Vidal, L. (Org.). Grafismo Indigena (pp.231-248). São Paulo, Studio Nobel/EDUSP/FAPESP.

Munita, C., Silva, M. A., Silva, F. A., \& Oliveira, P. M. S. (2005). Archaeometric study of clay deposits from indigenous land of the Asurini do Xingu. Instrumentaion Science and Technology, 33, 161-173.

Nelson, B. A. (1991). Ceramic frequency and use-life: A highland Mayan case in cross cultural perspective. In W. A. Longacre (Ed.), Ceramic ethnoarchaeology (pp. 162-181). Arizona: University of Arizona Press.

Neupert, M. A., \& Longacre, W. A. (1994). Informant accuracy in pottery use-life studies: A Kalinga example. In W. A. Longacre, \& J. M. Skibo (Eds.), Kalinga ethnoarchaeology: Expanding archaeological method and theory (pp. 71-82). Washington, D.C.: Smithsonian Institution Press.

Pryor, J., \& Carr, C. (1995). Basketry of Northern California Indians. In C. Carr, \& J. E. Neitzel (Eds.), Style, society and person. (Archaeological and Ethnological Perspectives) pp. 259-296. New York/ London: Plenum Press.

Ribeiro, B. G. (1982). A Oleira e a Tecelã. Revista de Antropologia, 26, 25-61 São Paulo.

Rice, P. (1987). Pottery analysis. A sourcebook. Chicago: University of Chicago Press.

Roe, P. G. (1995). Style, society, myth, and structure. In C. Carr, \& J. Neitzel (Eds.), Style, society and person. Archaeological and ethnological perspectives (pp. 27-76). New York: Plenum Press.

Schiffer, M. B. (1983). Toward the identification of formation processes. American Antiquity, 48, 675-706.

Schiffer, M. B. (1987). Formation processes of the archaeological record. Albuquerque: University of New Mexico Press.

Schiffer, M. B. (1995). Archaeological context and systemic context. In M. B. Schiffer (Ed.), Behavioral archaeology. First Principle (pp. 25-34).

Schiffer, M. B., Downing, T. E., McCarthy, M. (1995). Waste not, want not: An ethnoarchaeological study of reuse processes in Tucson, Arizona. In M. B. Schiffer (Ed.), Behavioral Archaeology. First Principles (pp. 107-120).

Schiffer, M. B., \& Skibo, J. (1987). Theory and experiment in the study of technological change. Current Anthropology, 28(5), 595-622.

Schiffer, M. B., \& Skibo, J. (1997). The explanation of artifact variability. American Antiquity, 62(1), $27-50$.

Shennan, S. (1992). Arqueología Cuantitativa. Barcelona: Editorial Crítica.

Shott, M. J. (1996). Mortal pots: On use life and vessel size in the formation of ceramic assemblages. American Antiquity, 61(3), 463-482.

Silva, F. A. (2000). As tecnologias e os seus significados. Um estudo da cerâmica dos Asuriní do Xingu e da cestaria dos Kayapó-Xikrin sob uma perspectiva etnoarqueológica. PhD Tesis. Universidade de São Paulo, São Paulo.

Silva, F. A. (2003). Cultural behaviors of indigenous populations and the formation of the archaeological record in Amazonian Dark Earth: The Asurini do Xingu Case Study. In J. Lehmann, D. Kern, B. Glaser, \& W. L Woods (Eds.), Amazonian Dark Earths. Origin, properties, management. Dordrecht/ Boston/London: Kluwer Academic Publishers.

Silva, F. A., Appoloni, C.R., et al. (2004). A Arqueometria e a Análise de Artefatos Cerâmicos: Um Estudo de Fragmentos Cerâmicos Etnográficos e Arqueológicos por Fluorescência de raios X (EDXRF) e Transmissão Gama. Revista de Arqueologia. Sociedade de Arqueologia Brasileira, n. 17:41-62.

Sinopoli, C. M. (1991). Approaches to archaeological ceramics. New York: Plenum Press.

Skibo, J. (1992). Pottery function: A use-alteration perspective. New York: Plenum Press. 
Skibo, J. M. (1999). Pottery and people. In J. M. Skibo, \& G. M. Feinman (Eds.), Pottery and people. A dynamic interaction (pp. 1-8). Salt Lake City: The University of Utah Press.

Skibo, J. M., \& Blinman, E. (1999) Exploring the origins of pottery on the Colorado Plateau. In J. M. Skibo, \& G. M. Feinman (Eds.), Pottery and people. A dynamic interaction. Salt Lake City. The University of Utah Press. Pp.

Skibo, J. M., \& Schiffer, M. B. (2001). Understanding archaeological variability and change: A behavioral framework. In M. B. Schiffer (Ed.), The anthropology of technology (pp. 139-149). Albuquerque: University of New Mexico Press.

Sullivan III, A. P. (1989). The technology of ceramic reuse: Formation processes and archaeological evidence. World Archaeology, 21(1), 101-114.

van der Leeuw, S. (1993). Giving the potter a choice. In P. Lemonnier (Ed.), Technological choices. Transformation in material cultures since the neolithic (pp. 238-288). London: Routledge.

Vidal, L. B., \& Müller, R. P. (1986). Pintura e Adornos Corporais. In: B. Ribeiro (coord.). Suma Etnológica Brasileira (Arte Indígena), Vol. 3. Vozes/FINEP, Petrópolis, pp.119-148.

Yellen, J. (1977). Archaeological approaches to the present. Models for reconstructing the past. New York: Academic Press. 